\title{
EL TEATRO DE ÓPERA. Acondicionamiento del Teatro Lírico Nacional "La Zarzuela"
}

\section{(OPERA THEATRE. The conditioning of "La Zarzuela" Lyrical Theatre)}

\section{RESUMEN}

Se describe, en este articulo, la reforma y restauración del Teatro Lirico Nacional "La Zarzuela" de Madrid. Las obras duraron desde 1983 a 1987.

Esta reforma ha comprendido diversos e importantes aspectos. Los más significativos han sido los referidos al funcionamiento de los medios técnicos del escenario, que han supuesto una profunda transformación en su estructura $y$ en su equipamiento.

Estas obras, que se describen posteriormente, han ido acompañadas de otras de orden estético como: pinturas, tapizados, moquetas, butacas e iluminación exterior de la fachada, etcétera.

\section{SUMMARY}

This article describes the reform and restoration has been made in the Nacional Lyrical Theatre "La Zarzuela" of Madrid. This works lasted since 1983 until 1987.

This reform has meant several and important changes, specially to the functionning of the stage technical means.

This has supposed a great change in its structure and equipment. There have been other changes also, specially aesthetical, as paintings and tapestry, stalls and carpets. The lighting up of the facade has also been improved.

\section{SITUACIÓN}

El Teatro Lírico Nacional "La Zarzuela" se sitúa en la manzana comprendida entre las calles de Jovellanos, Los Madrazo, Cedaceros y Zorrilla. Tiene su entrada principal (de público) por Jovellanos; la de artistas y escenario por Los Madrazo.

\section{ANTECEDENTES HISTÓRICOS*}

Dado el éxito que a mediados del siglo XIX acompañaba a las representaciones de zarzuela, Francisco de Rivas encargó al santanderino Jerónimo de la Gándara, en 1856, la construcción del Teatro de "La Zarzuela", con el apoyo de la Sociedad "La España Musical". Las obras duraron siete meses.

El modelo a seguir fue la Scala de Milán proyectada por Giuseppe Piermani, en 1776, siendo la planta una trasposición de la italiana.

El único alzado exterior del Teatro es obra de José M. ${ }^{a}$ Guallart, quien lo redefinió a partir del que inicialmente había proyectado Jerónimo de la Gándara.

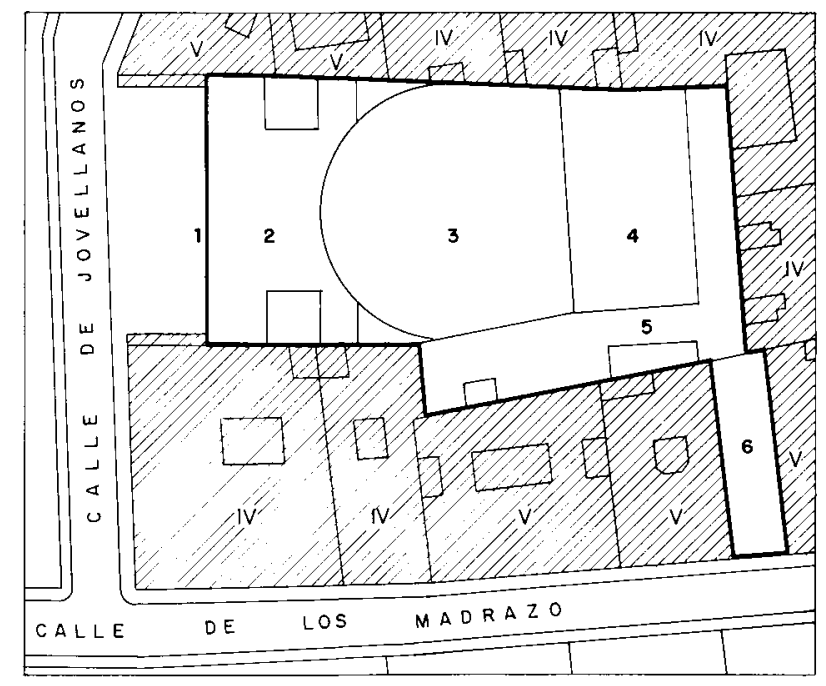

Plano de situación

1.- Fachada a la calle de Jovellanos. 2.-Vestibulos. 3.-Sala General de público. 4.-Escenario. 5.-Zona de camerinos. 6.-Salida a la calle de Los Madrazo.

El Teatro sufrió un incendio en noviembre de 1909, que lo destruyó casi en su totalidad, con la excepción de la obra de fábrica exterior e interior. Gracias a esto las posteriores construcciones pudieron mantener siem. pre el trazado en planta y fachadas originales. 
En 1910, el arquitecto Cesáreo Iradier es el encargado de realizar el proyecto de reconstrucción del Teatro. La nueva estructura, ahora metálica, permitió algunas variaciones que afectan fundamentalmente al vuelo de la galería, forma de la cubierta y movimiento escénico. También varió Iradier la disposición de las plateas en planta baja, camerinos y otras dependencias.

En 1956, y coincidiendo con el centenario de su cons. trucción y fundación, Vallejo y Dampierre lo remodelan de modo que hacen desaparecer la decoración introducida por Iradier y transforman las escaleras de la zona de público, que son las que hoy podemos apreciar.

A comienzos de los años 70 se produce una reforma de las pasarelas de la caja del escenario o telares, permaneciendo la estructura de la cubierta de elementos metálicos implantada por Iradier.

\section{OBRAS REALIZADAS}

Las obras llevadas a cabo, y que a continuación se describen, han sido ejecutadas entre 1983 y 1987.

\section{Reforma del escenario}

Anteriormente se mencionaba que la cubierta del escenario la construyó Cesáreo Iradier, en 1910. El peine es el elemento de la tramoya que, teniendo una configuración a modo de parrilla, sustenta todos los elemen. tos escénicos (decorados, luces, bambalinas, etc.), siendo éste de madera en el momento previo a realizar la reforma, datando su construcción de 1910.

En 1985 se encontraba muy deteriorado y obsoleto debido a que el tipo de espectáculos que se desarrollan en este Teatro: óperas, ballets y zarzuelas tienen, hoy

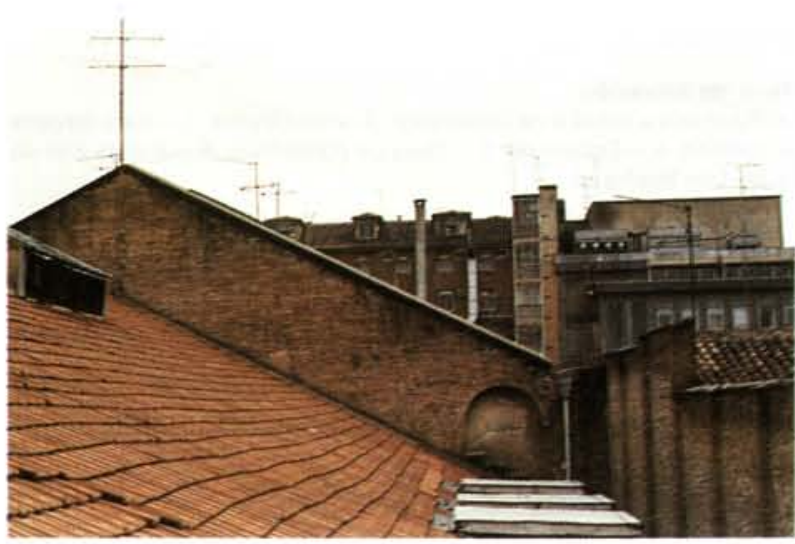

1. Cubierta del escenario antes de la reforma.

(C) Consejo Superior de Investigaciones Científicas Licencia Creative Commons 3.0 España (by-nc) por hoy, una configuración que requieren no sólo la utilización de peines metálicos, sino además la introducción de elementos de contrapeso que hagan más cómodo y factible el movimiento escénico de decorados, luces, etcétera.

Otro problema que planteaba el peine antiguo era su altura, de 17,25 m con relación a la cota de escena. Al ser la altura de la embocadura de $8,25 \mathrm{~m}$, el peine estaba a poco más del doble de la misma, lo que llevaba consigo que los telones y decorados no "escondieran" bien, produciéndose desde las primeras filas la visión de éstos. Para evitarlo se colocaban bambalinas intermedias que disminuian la altura escénica considerablemente.

Con esta reforma no sólo se dispone de un peine metálico, sino que además se ha conseguido que su altura sea de $23,72 \mathrm{~m}$, con lo que la proporción es de tres veces la altura de la embocadura, eliminando asi el pro. blema anteriormente expuesto.

Para conseguir este objetivo fue necesario realizar una estructura metálica nueva que, apoyada en los gruesos muros del escenario, sobrepasara en altura la cubierta primitiva (fotos 1 y 2 ).

Sobre pilares metálicos se apoyaron las cerchas que iban a servir para la configuración de la nueva cubier. ta y ser el sustento del nuevo peine y toda la maquina. ria precisa para el trabajo escenográfico.

Fue de enorme dificultad y complejidad el montaje de esta estructura, habida cuenta de la problemática que suponia moverse en un edificio rodeado de mediane. ras y a $38 \mathrm{~m}$ desde la calle de Jovellanos.

Ante la imposibilidad de poder trabajar con grúa, se hizo un diseño de la estructura que pudiera ser montada como un mecano y llevada a mano desde la fachada

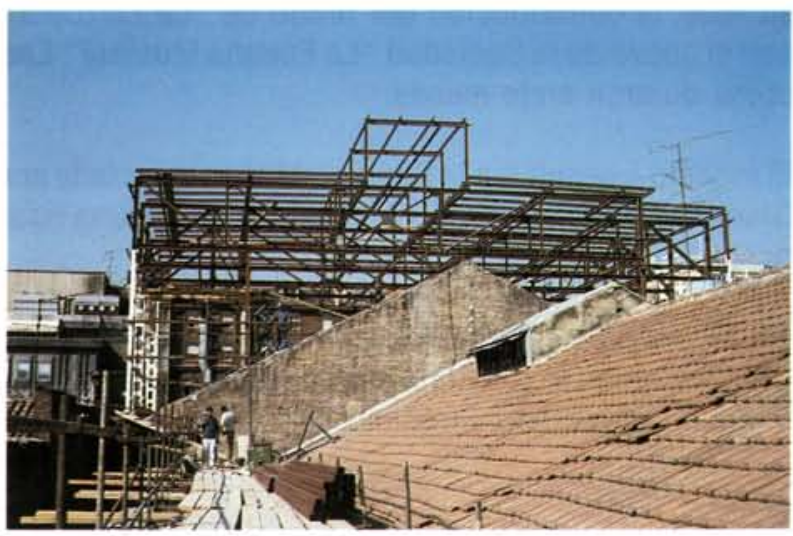

2. Vista general de la nueva estructura del escenario http://informesdelaconstruccion.revistas.csic.es 
de la calle Jovellanos hasta el escenario, por una pasarela construida a tal efecto, y que recorria toda la cubierta (fotos 2,3 y 5 ) subiendo el material en un montacargas por la fachada.

Se realizaron también nuevas pasarelas de trabajo. Anteriormente tan sólo existian las pasarelas que, según su cota de altura referidas al escenario, eran $+7,67$; $+9,87$ y $+13,53$, construyéndose otras nuevas a $+16,78$, $+20,20$ y $23,72 \mathrm{~m}$, que es la cota del nuevo peine.

Posteriormente se realizaron los trabajos de desmontaje de la cubierta antigua. Se procedió, en primer lugar, a la demolición del entramado de madera que configuraba el peine primitivo para a continuación cortar las cerchas de sus extremos, bajarlas con trácteres anclados en la nueva estructura y trocearlas en el escenario (fotos $6,7,8$ y planos de las páginas 40 y 41 ). De esta forma quedó limpia la nueva caja del escenario.

Posteriormente se demolieron elementos que limitaban el espacio, como la antigua cabina de control de luces (foto 9). Una vez realizados, en el escenario, los trabajos de limpieza y demolición se empezaron a ejecutar los de dotación y equipamiento. En las pasarelas de la derecha (según se mira al espectador) se realiza el trabajo de contrapeso de decorados, otra de las mejoras introducidas.

La elevación de decorados se hacia anteriormente en directo, es decir, que para elevar un decorado no habia ningún medio mecánico de ayuda, teniéndose que hacer un esfuerzo de subida igual al peso del elemento. Esto, cuando las piezas pesaban poco, no ofrecia excesivo problema, pero los montajes actuales son más complejos y con piezas o elementos que, incluso, llegan a pesar $2.000 \mathrm{~kg}$. Para ello se ha introducido maquinaria de contrapesado. Ésta tiene como objetivo equilibrar el peso del decorado, siendo el esfuerzo humano del tramoyista prácticamente nulo, permitiendo ahorrar tiempo, trabajo y esfuerzo humanos (foto 10 ).
Concretamente se han conseguido 77 barras contrapesadas (foto 11) (punto 12 del plano de la página 41), tres de ellas motorizadas, es decir, su maniobra no es manual, sino a través de motores. La capacidad de la carga de cada barra es de $500 \mathrm{~kg}$. De esas 77, se pueden dedicar 11 a ser barras de luces o barras para colgar focos con distintas tomas eléctricas en las mismas.

Paralelamente a la labor de ejecución del peine metálico se ha realizado una electrificación del mismo, con objeto de canalizar - según la Normativa vigente - las distintas tomas de corriente y las redes eléctricas a nivel de peine, y de las distintas pasarelas de trabajo dentro del escenario.

Se han instalado otros cuatro motores llamados de "boca a fondo" que, al ser deslizables por unas guías-carril, permiten ubicarlos donde se quiera y que, enfrentados al corte de barras que se desee, queda motorizado cualquier corte, permitiendo incluso ser aptos para varias maniobras distintas:

a) Poder elevar puntualmente y sin necesidad de barra cualquier elemento.

b) Compaginar conjuntamente la maniobra de varios motores a la vez: sabiendo que cada uno levanta $500 \mathrm{~kg}$ se podría, al tener cuatro, subir motorizados a la vez hasta $2.000 \mathrm{~kg}$.

Esta maniobra se realiza desde cuadros eléctricos instalados en las pasarelas de trabajo y contrapesado, en este caso la $+9,87$.

c) Con estos motores conceptualmente se ha conseguido que cualquier corte pueda ser motorizado, contrapesado y ser incluso apto para el uso de manuales.

Se ha construido, sustituyendo a una pasarela fija que corria de lado a lado de ancho del escenario, un puen-

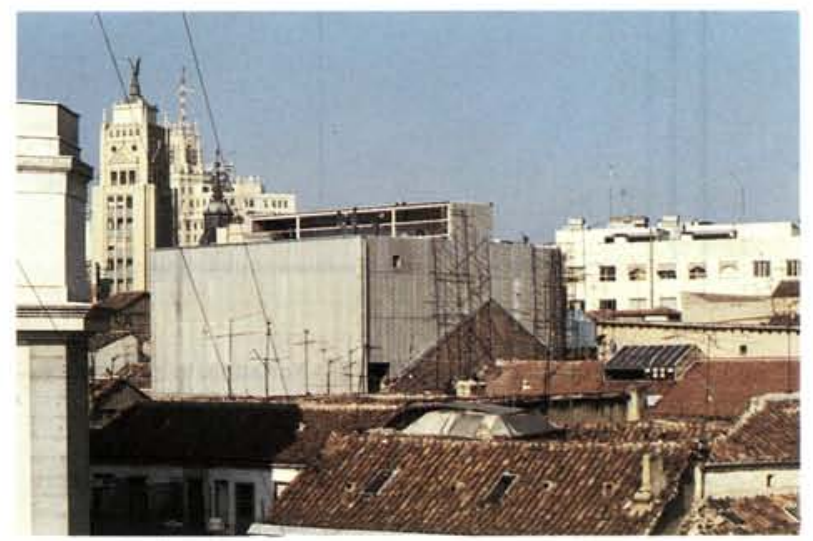

3 y 4 . Vista general de la nueva caja del escenario (estado definitivo).

(C) Consejo Superior de Investigaciones Científicas http://informesdelaconstruccion.revistas.csic.es Licencia Creative Commons 3.0 España (by-nc) 
te móvil de luces movido con motor hidráulico, que tiene un recorrido desde la cota $+0,00$ hasta la cota $+14,54 \mathrm{~m}$ de altura, no condicionando de esta forma la altura de la escena, como ocurría con anterioridad ai estar dicha pasarela fija a $+7,67$. Este puente de luces sive para dotar a la escena de un mayor número de focos según las necesidades de cada representación (foto 12).

\section{Estado primitivo}

Sección C - D

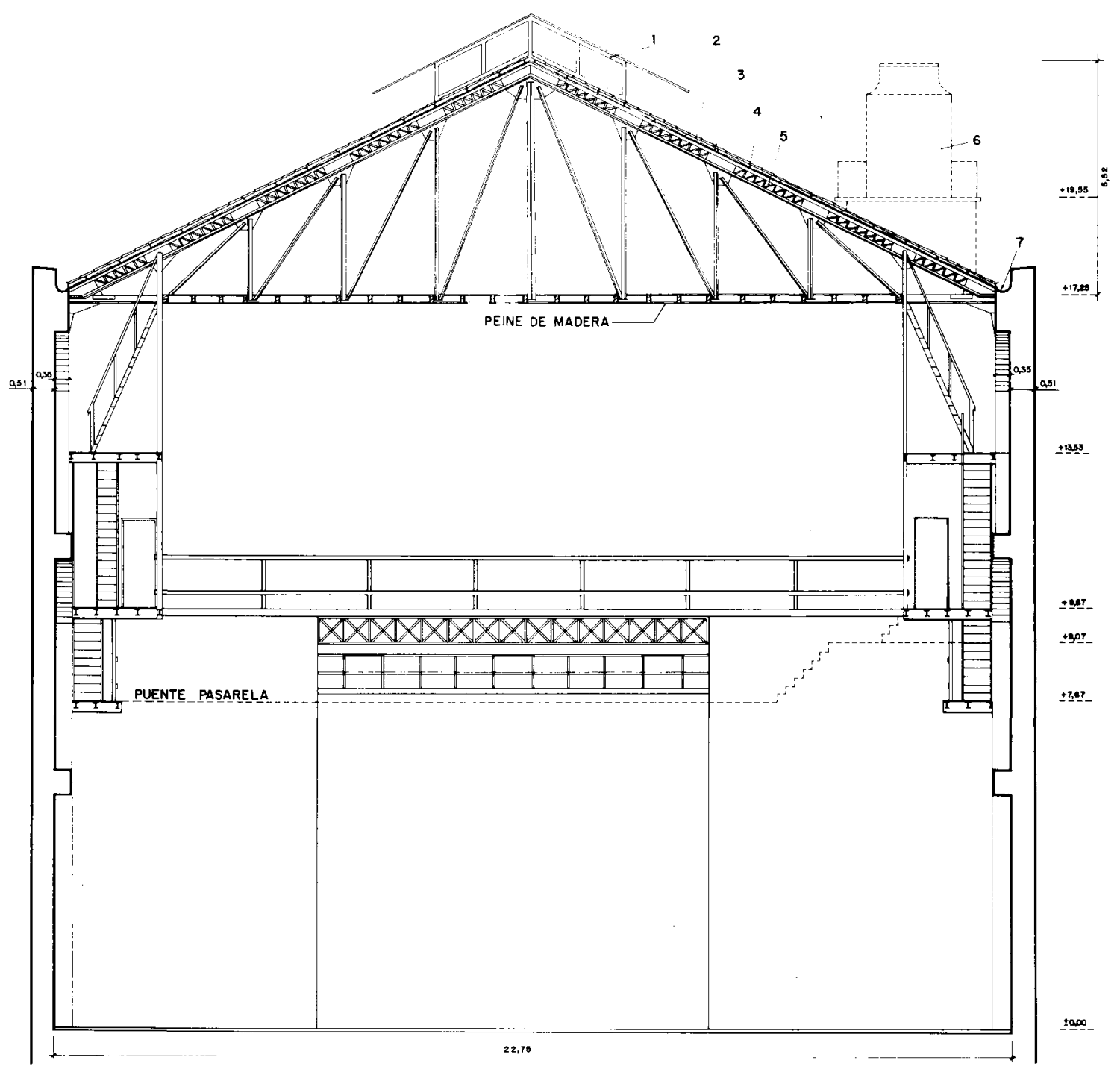

1.-Lucernario. 2.-Teja plana. 3.-Forjado a la catalana. 4.-IPN 100. 5.-Cercha metálica. 6.-Torre de refrigeración. 7.-Canalón de cinc. 


\section{Estado definitivo}

Sección C - D

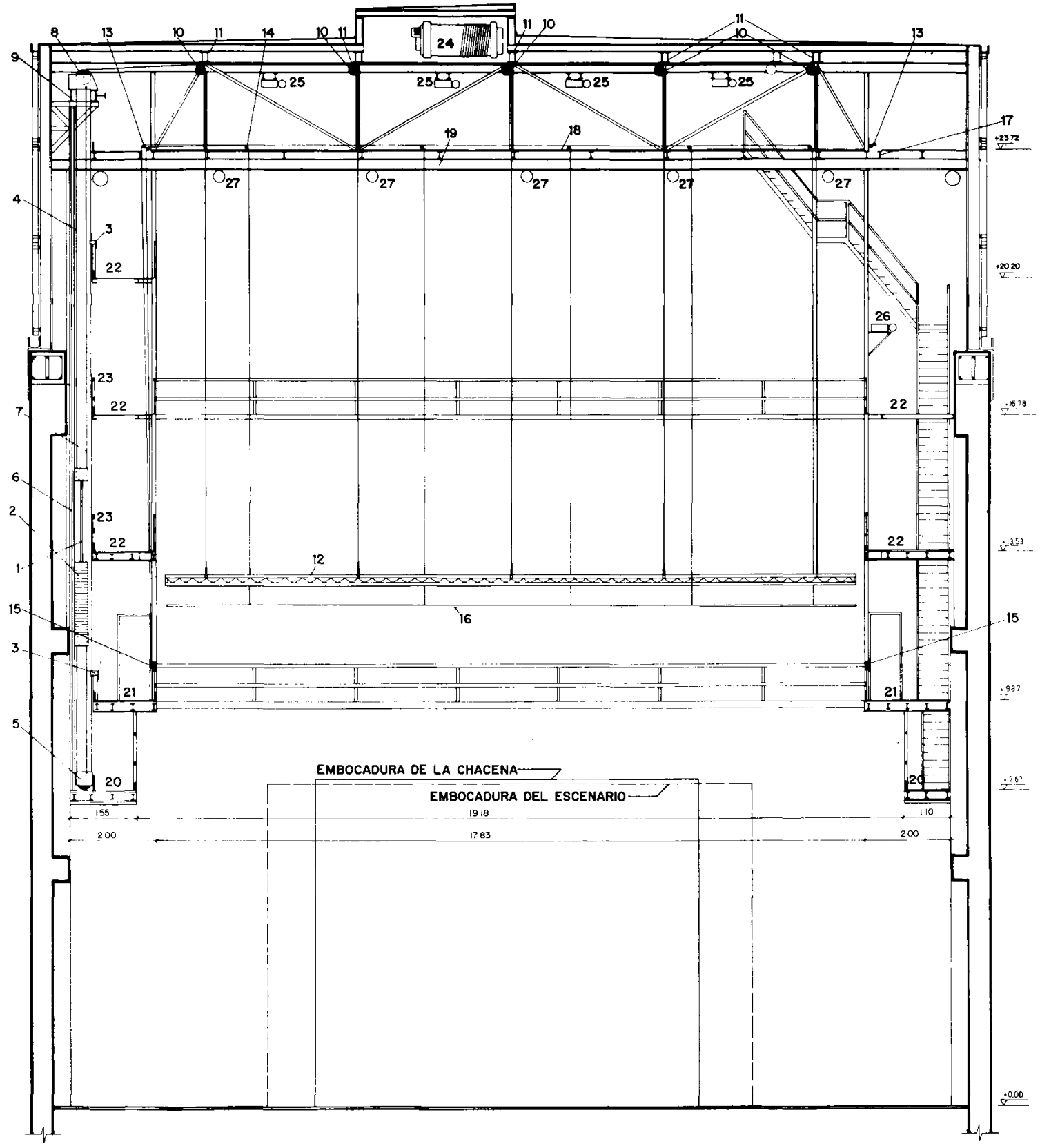

1.- Carro contrapesado. 2.-Contrapeso. 3.-Freno. 4.-Maromillo. 5.-Polea de reenvio. 6.-Guía de carro. 7.-Cable. 8.-Polea de cabeza. 9.-Bancada de polea de cabeza. 10.-Polea de tiro. 11.-Bancada de poleas de tiro. 12.-Barra contrapesada. 13.-Desembarco manual. 14.-Tiro manual. 15.-Aspas de atado (Sistema manual). 16. - Barra manual. 17.-Bancada de desem barco manual. 18.--Peine. 19.-Estructura de soporte del peine. 20.-Galeria eléctrica (existente). 21.-Galeria de trabajo (exis. tente). 22.-Galería de carga (existente $=+13,53 \mathrm{~m}$, nuevas $=+16,78+20,20+23,72 \mathrm{~m}$ ). 23. - Barandillas de protección 24.-Tambor de enrollamiento del cable eléctrico. 25.-Motores boca a fondo. 26.-Motores de los cortes especiales. 27.-Poleas de los cortes especiales. 


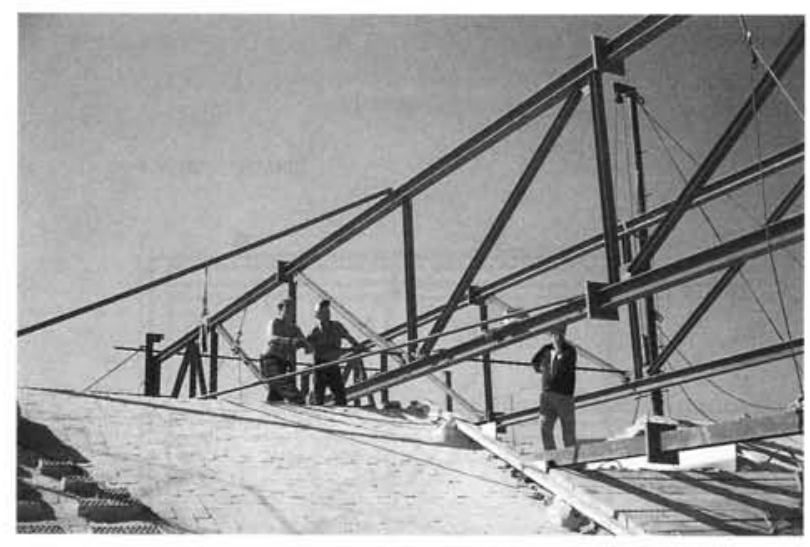

5. Montaje de estructura metálica.

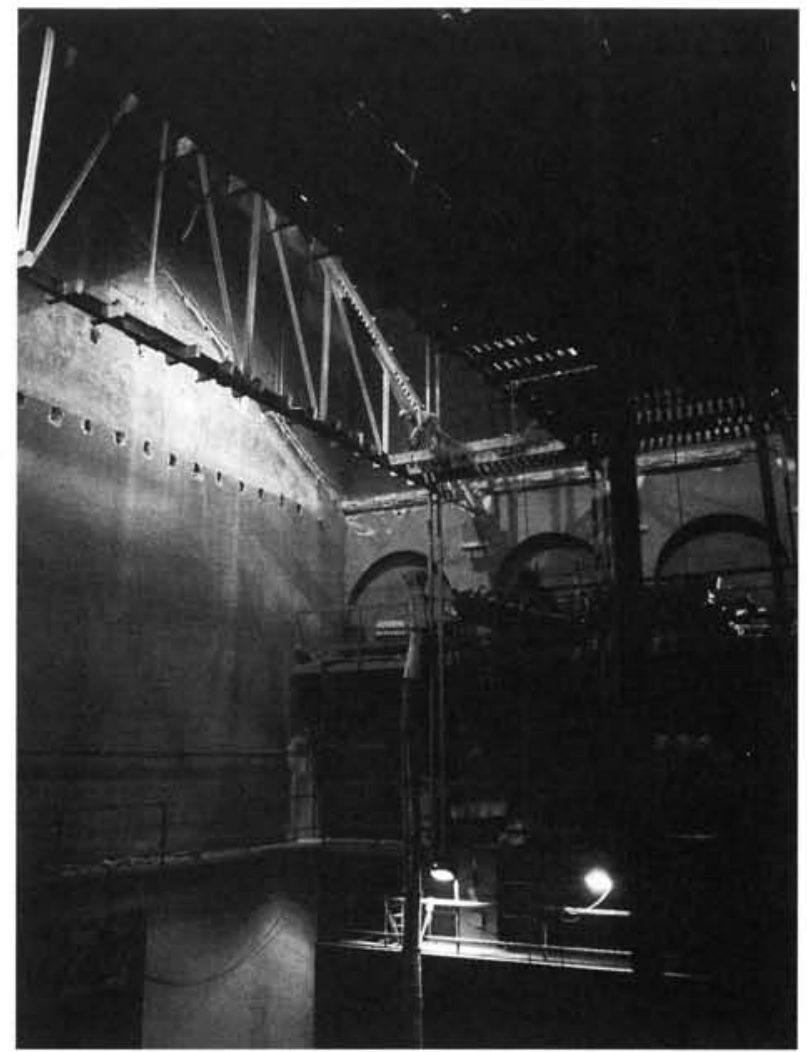

6. Trabajos de demolición dentro del escenario.

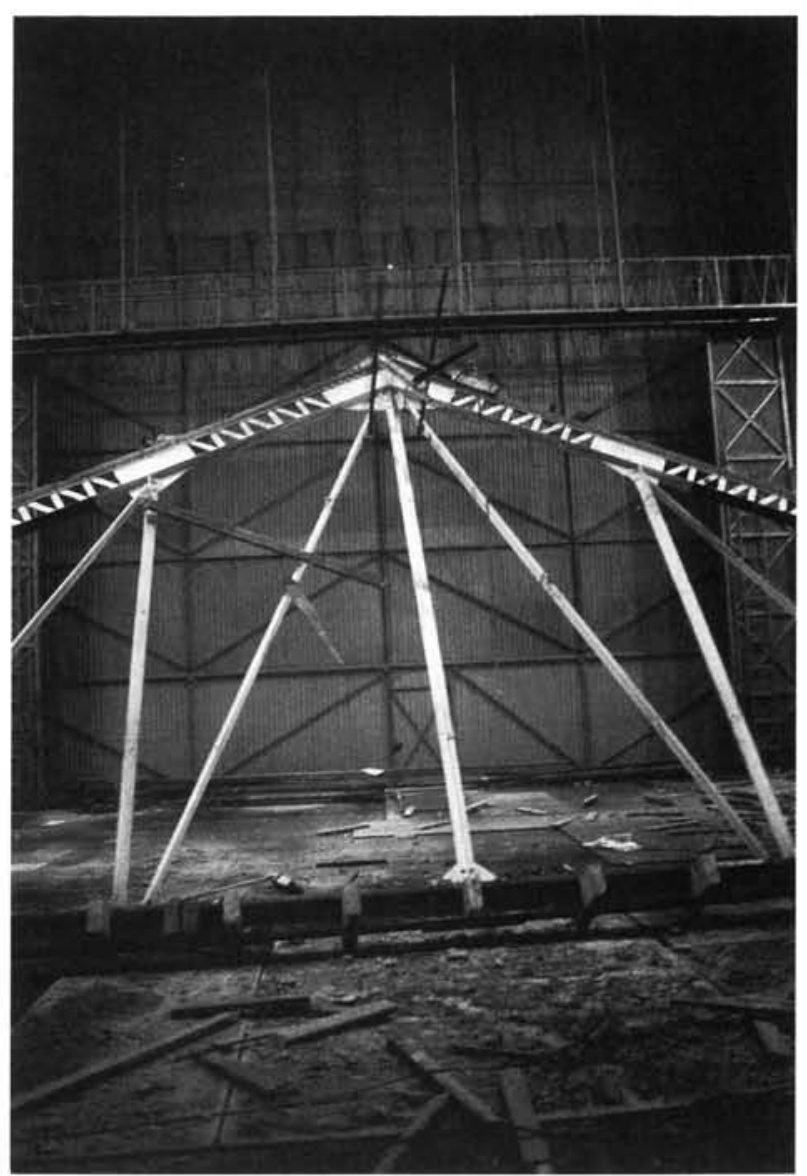

7 y 8 . Vistas de los trabajos de desmontaje de la antigua estructura.

(c) Consejo Superior de Investigaciones Científicas Licencia Creative Commons 3.0 España (by-nc) 


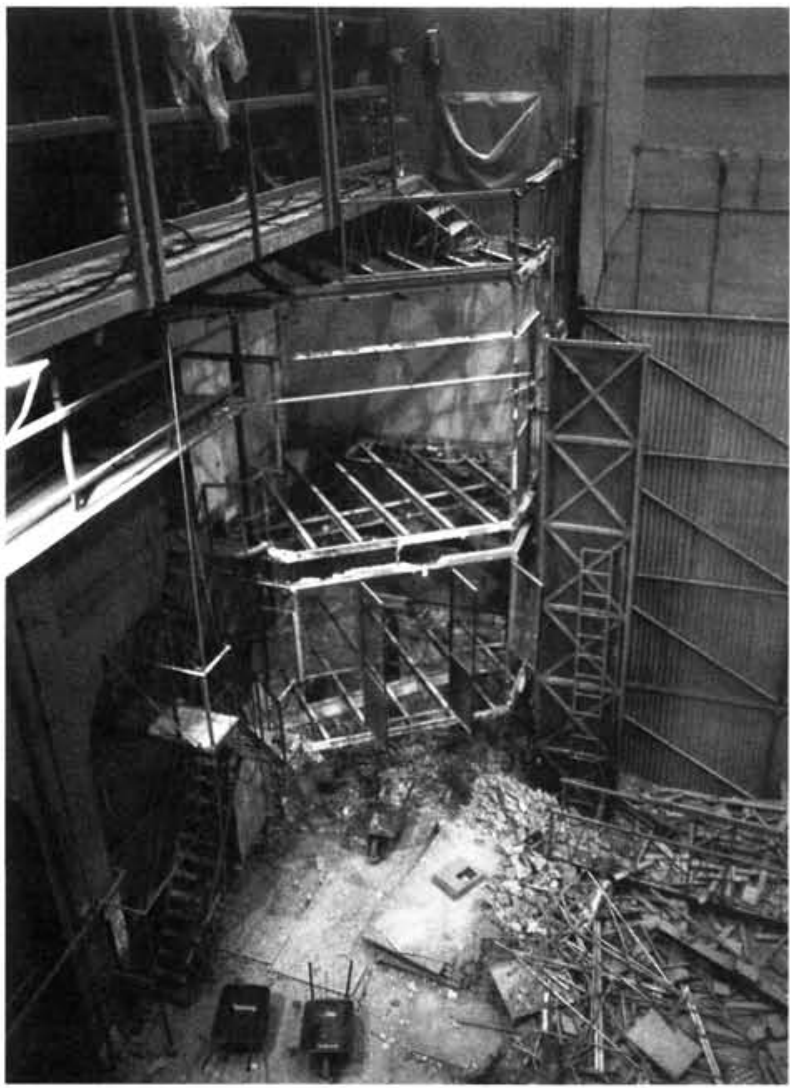

9. Trabajos de demolición dentro del escenario (demolición de la antigua cabina de control de iluminación).

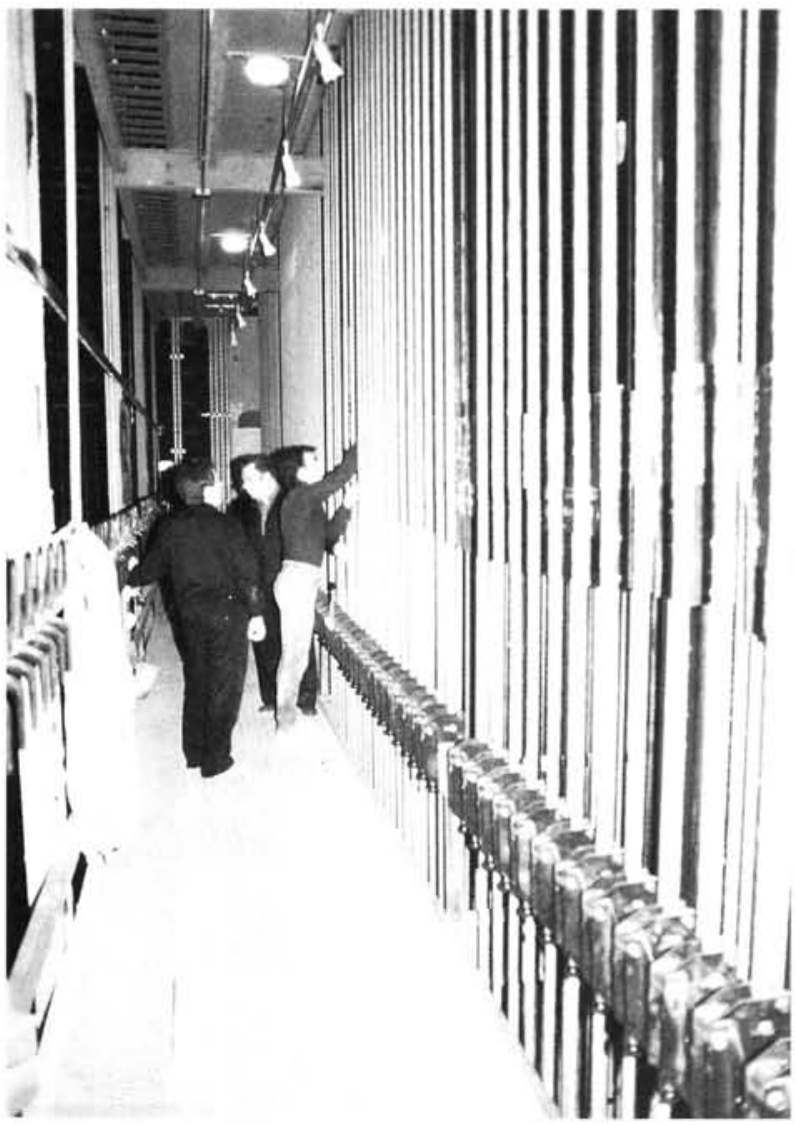

10. Galeria de contrapesado.

(C) Consejo Superior de Investigaciones Científicas Licencia Creative Commons 3.0 España (by-nc)

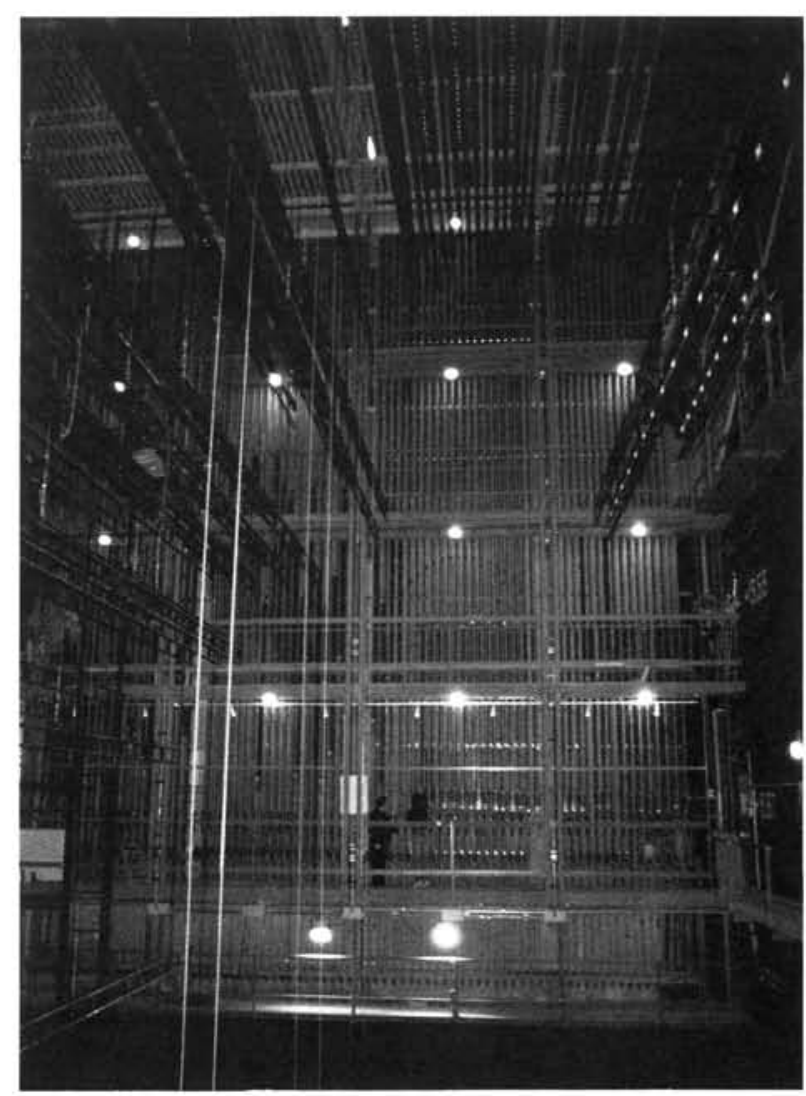

11. Vistas interiores del escenario, una vez restaurado (zona de contrapesos).

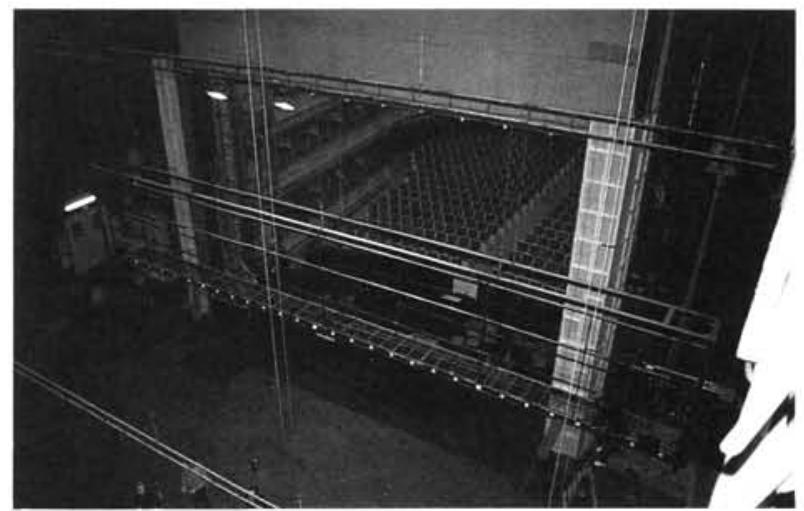

12. Vista interior del escenario, una vez restaurado (puente de luces).

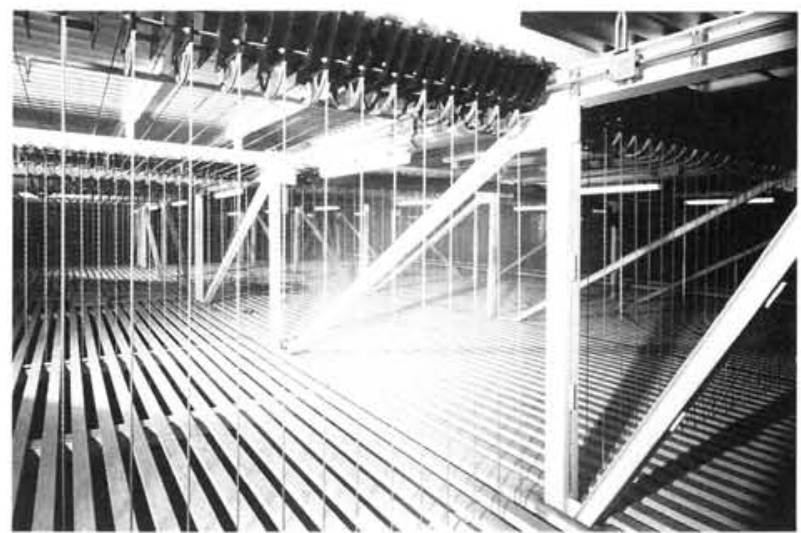

13. Vista general del nuevo peine metálico

http://informesdelaconstruccion.revistas.csic.es 


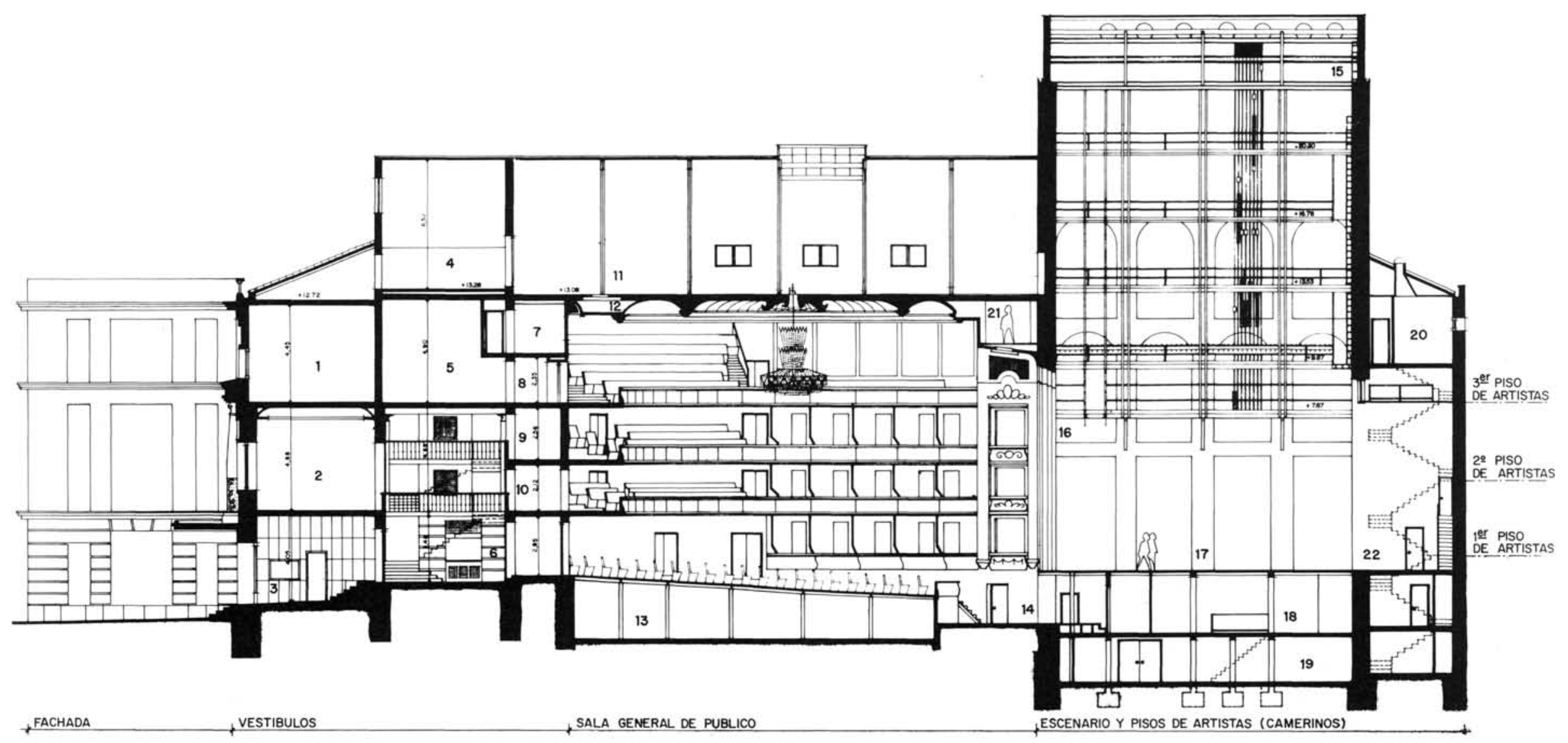

1.-Sala de ensayos de ballet. 2.-Bar (preferencia). 3.-Hall. 4.-Antigua sala de ensayo de coros. 5.-Guardarropa. 6.-Vestibulo. 7.-Cabina. 8.-3. ${ }^{\text {er }}$ anfiteatro. 9.-2. ${ }^{\circ}$ anfiteatro. 10.-1.et anfiteatro 11.-Desván. 12.-Galeria. 13.-Foso patio butacas. 14.-Orquesta. 15. - Peine (+23,72 m). 16. - Puente de luces. 17. - Escenario. 18. - Foso. 19.-Contrafoso. 20.-Vestuarios de electricistas y tramoyistas 21.-Galeria de focos. 22.-Chácena. 


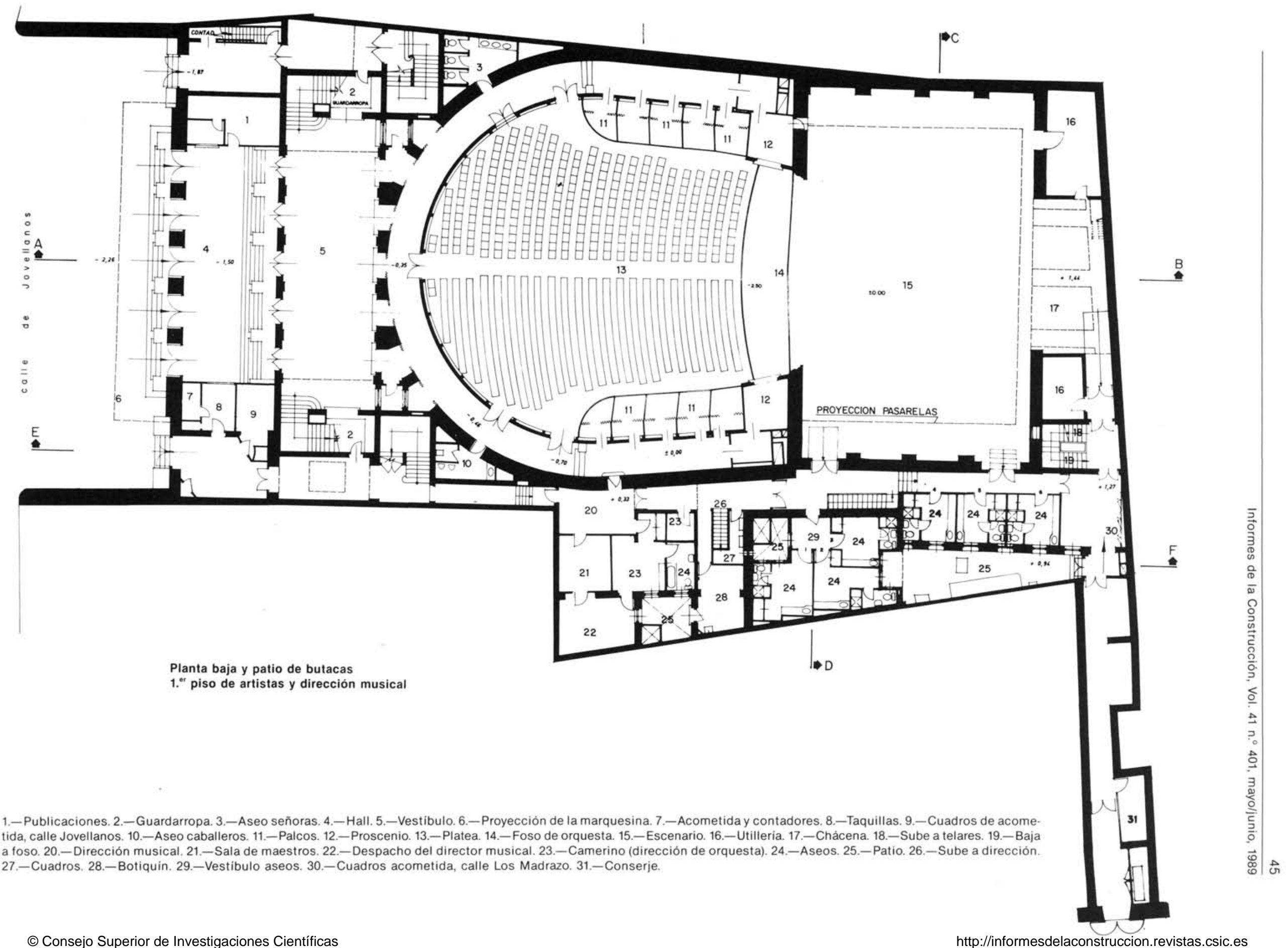




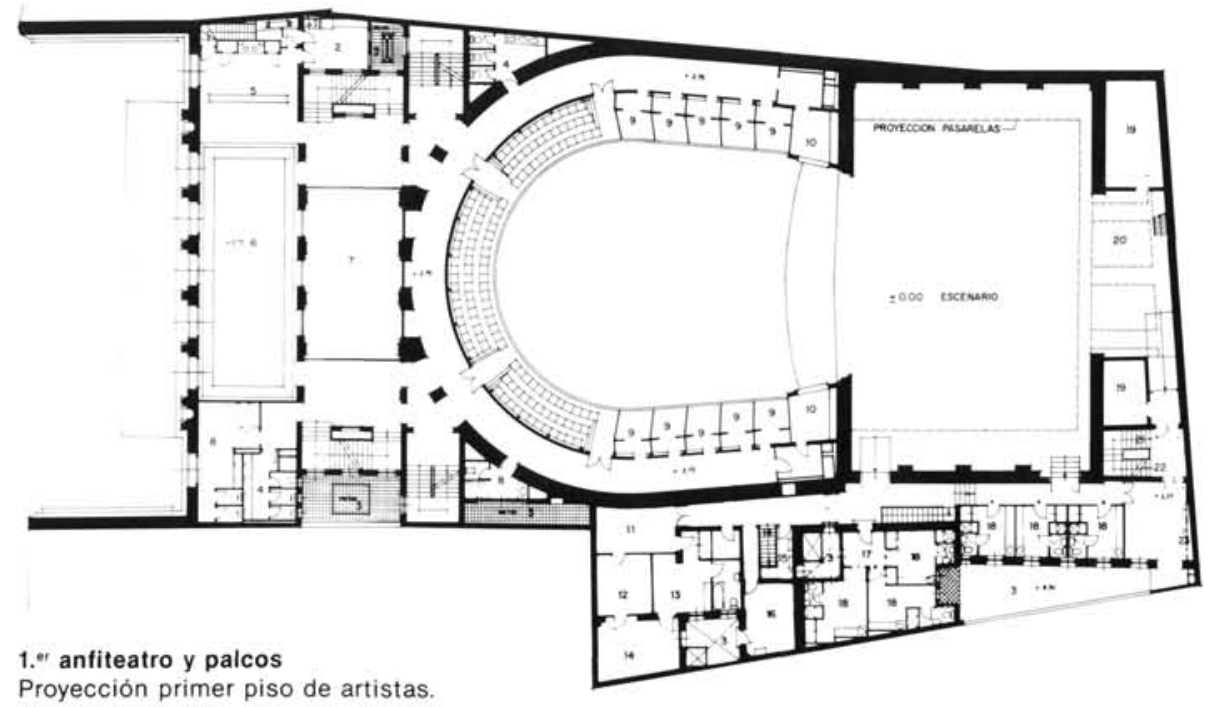

1.-Oficio. 2.-Cocina. 3.-Patio. 4.-Aseo señoras. 5.-Barra. 6.-Salón-bar. 7-Vacio vestibulo. 8.-Aseo caballeros. 9.-Palcos. 10.-Proscenio. 11.-Dirección mu. sical 12. Sala de maestros. 13.-Camerino de dirección de or. questa. 14.-Sube a dirección 15.-Cuadros. 16.-Botiquín. 17.Vestibulo de aseos. 18.-Aseos. 19.-Utilleria. 20.-Chácena. 21.-Su be a telares. 22.-Baja a foso. 23.-Cuadros acometida a calle

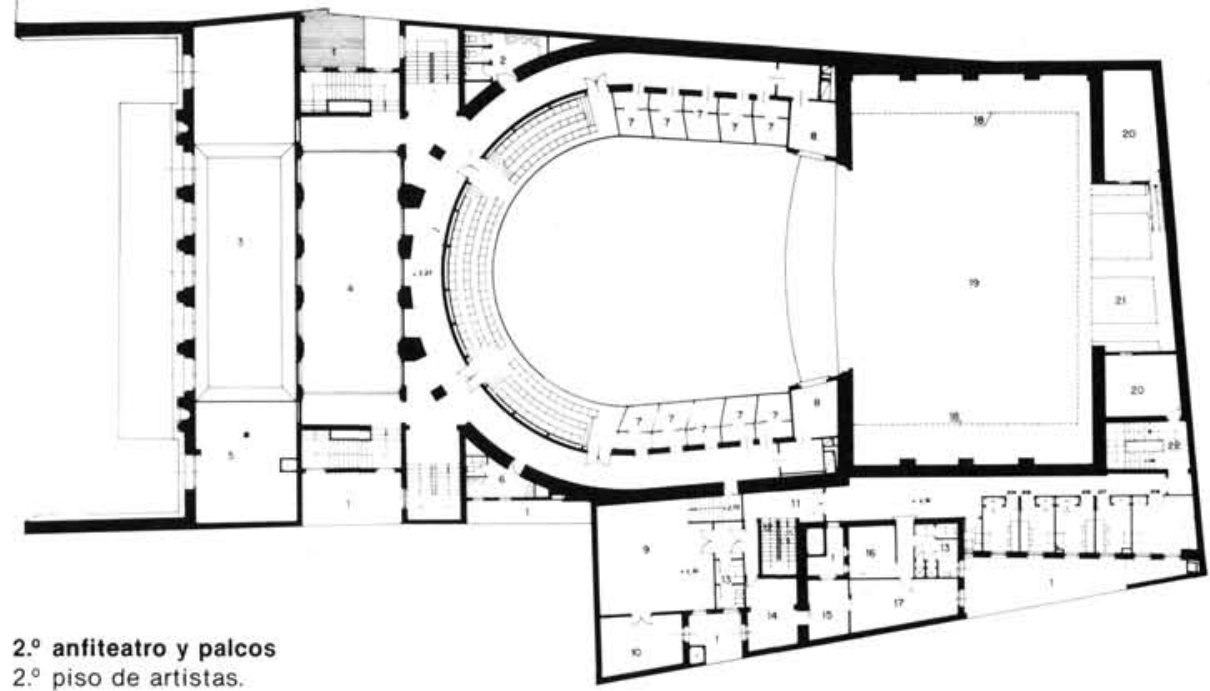

1.-Patio. 2.-Aseo señoras. 3.-Va. cio salón bar. 4.-Vacio vestibulo. 5.-Vacio aseo. 6.-Aseo caballeros. 7.-Palcos. 8.-Proscenio. 9.-Salón de recepciones. 10.-Despacho del sobreintendente. 11.-Di. rección. 12.-Sube a camerinos. 13-Aseos. 14-Secretaria. 15-Fotocopias y télex. 16.-Despacho. 17.-Administración y contabilidad. 18-Proyección pasarelas. 19.-Escenario. 20.-Utilleria.

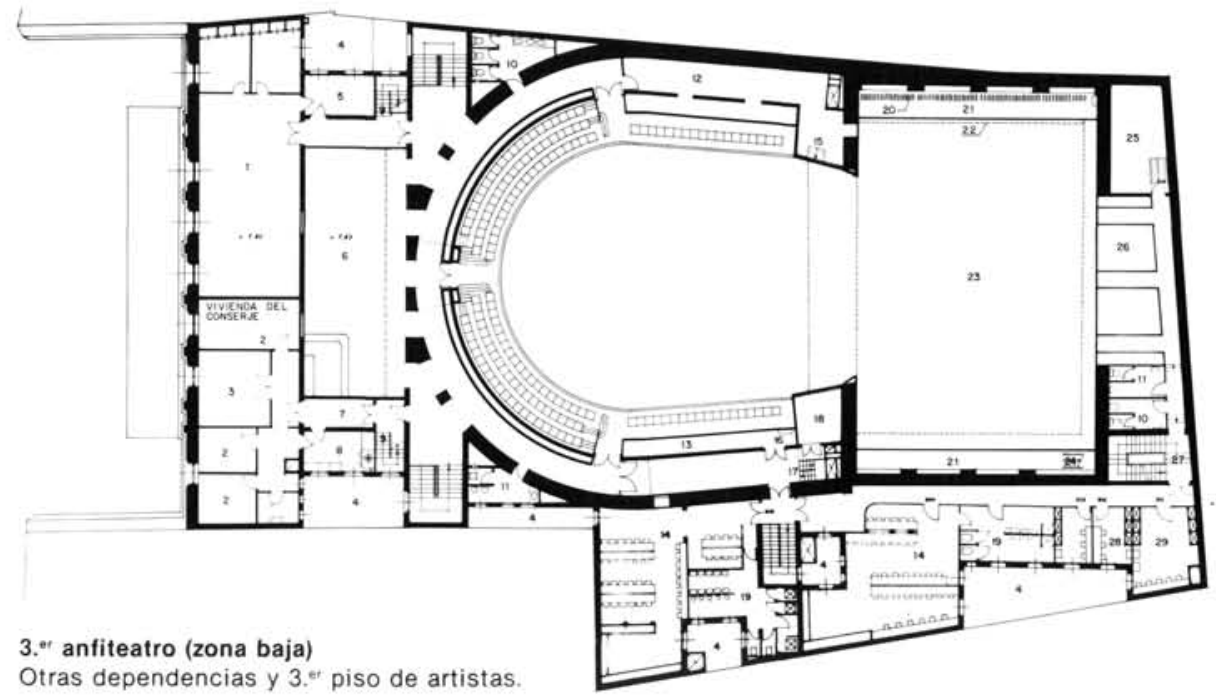

1.-Sala de ensayos. 2-Dormitorio. 3-Comedor 4-Patio. 5.-Despacho. 6.-Vestíbulo del 3. ${ }^{\circ}$ anfiteatro. 7.-Vestibulo. 8.-Cocina. 9--Sube a cabina. 10.-Aseos señoras. 11-Aseos caballeros. 12.-Almacén de tramoya. 13.-Almacén de electricidad 14.-Coros. 15.-Sube a galeria de embocadura. 16.-Sube a desván. 17.-Sube a entreplanta. 18.-Reactancia. 19.-Aseos. 20.-Poleas de reenvio. 21. Pasarela $+7,67$. 22.-Proyección pasarelas superiores. 23.-Escenario. 24.-Sube a $+9,87$. 25.-Almacén de focos. 26.-Chácena. 27.-Sube a telares. 28.- Peluqueria. 29.-Sastreria. 
1.-Vacio, sala de ensayos. 2.- $\mathrm{Pa}$. tio. 3.-Gabinete de grabación y so. nido. 4.-Vacio vivienda del conserje. 5.-Sube a desván. 6.-Cabina de control de grabación y sonido. 7.- Cabina de control de iluminación. 8.-Cuadros y dimmers. 9.-Almacén de tramoya. 10,-Entreplanta de comparsas. 11.-Co. ros. 12.-Aseos. 13.-Vacio reactancias. 14.-Poleas de reenvio. 15.-Pasarela $+7,67$. 16. - Proyección pasarelas superiores. 17.-Escenario 18-Sube a +9,87, 19-Pe luqueria. 20.-Almacén de focos. 21.-Chácena. 22.-Caballeros. 23. - Señoras. 24.-Sube a telares. 25.-Sastreria.

1.-Baldosin catalán. 2.-Teja cur. va. 3.-Teja plana. 4.-Émbolo del puente de luces. 5.-Viene de $+13,53$. 6. - Sube a peine.

1.-Baldosin catalán. 2.-Teja curva. 3.-Teja plana. 4.-Poleas de cabeza. 5.-Motor móvil (boca-fondo) 6.-Poleas de tiro (corta). 7.-Po. leas de tiro (centro-corta). 8.-Tam bores de enrollamiento de canalización eléctrica. 9.-Polipasto de sustentación de enrolladores. 10.-Poleas de tiro (central). 11.-Poleas de tiro (largo-central). 12.-Poleas de tiro (larga). 13.-Motor fijo. 3."r anfiteatro (zona alta)

Proyección tercer piso de artistas.

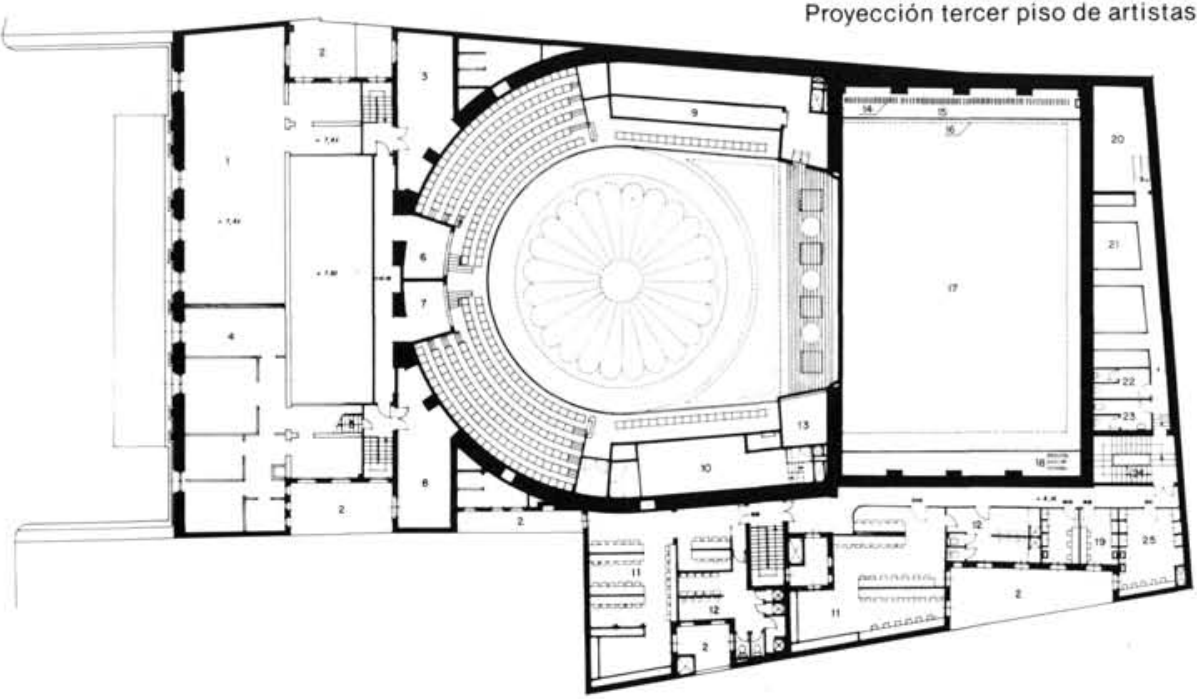

Planta de cubiertas

Corte del escenario a nivel de pasarelas

de trabajo.

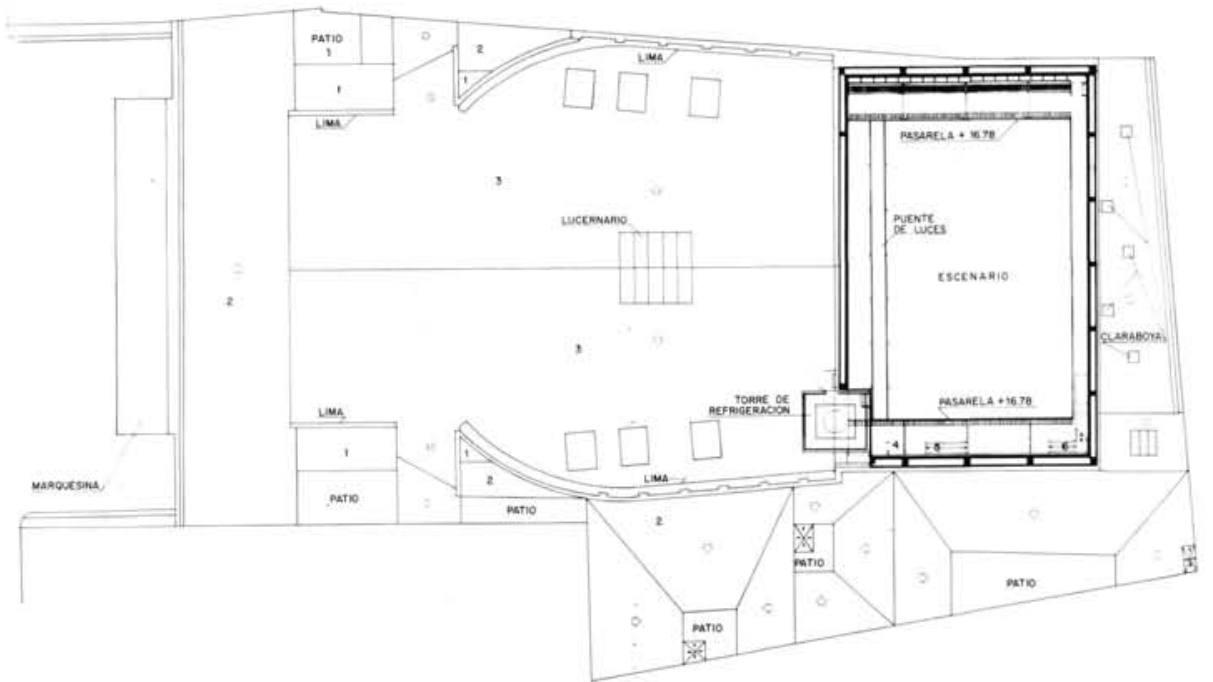

Planta de cubiertas

Corte del escenario a nivel de peine $(+23,72)$.

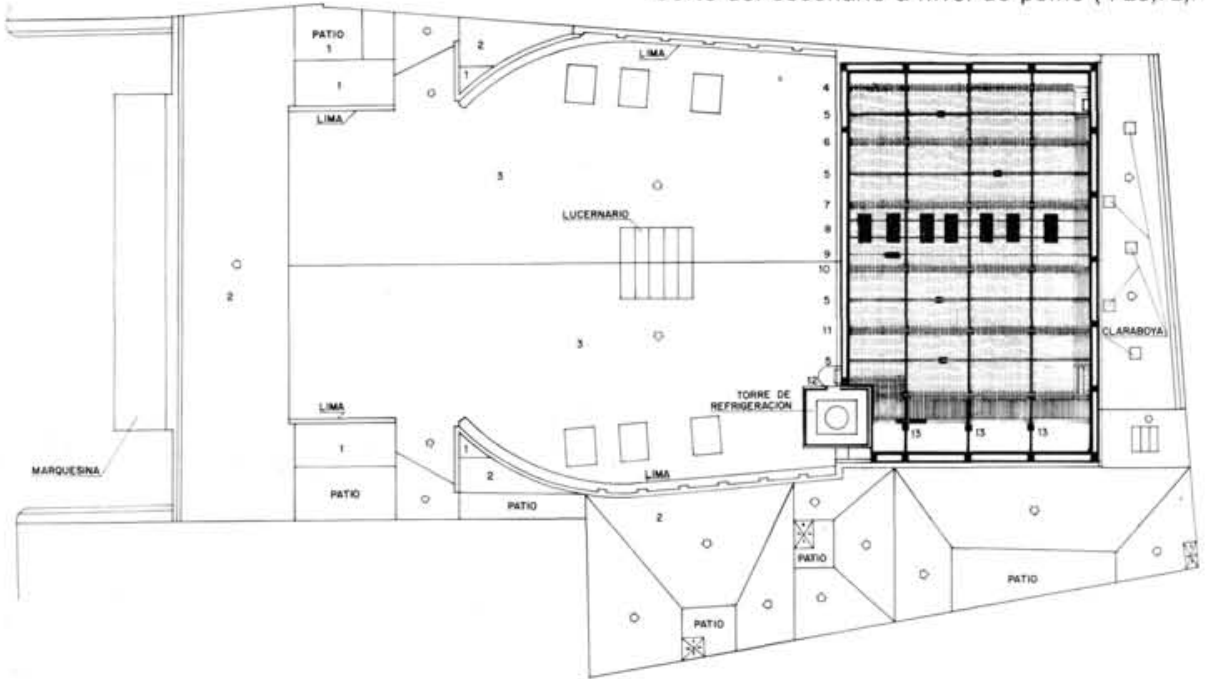

http://informesdelaconstruccion.revistas.csic.es 
Creación de las nuevas cabinas de control de iluminación, grabación de vídeo y sonido

Esta obra contempló lo que pudiéramos decir la segunda fase de la remodelación del escenario, sobre todo en lo relativo a las instalaciones de luminotecnia y electrotecnia del teatro, resolviendo las necesidades que las representaciones puedan exigir.

Resumiendo ha consistido en:

1) Nueva acometida general.

2) Renovación, a tal efecto, del cuadro general.

3) Nuevas líneas generales de alimentación a escenario y Sala.

4) Nuevos cuadros de encendido de escenario y Sala.

5) Cuadro de protección de circuito de proyectores.

6) Cuadros de fuerza.
7) Circuitos de enlace, cuadro circuitos-dimmers.

8) Circuitos de enlace armarios-dimmers, cuadros de cabina para regulación de escenario.

9) Instalación de tomas de microfonia, megafonia, intercomunicación, vídeo y TV.

10) Demolición de la vieja cabina de control que, estando dentro del escenario, ocupaba un volumen muy grande entorpeciendo el montaje de elementos de decorados cercanos a la embocadura.

11) Creación de una nueva cabina en la parte alta del 3." anfiteatro (foto 14) con dos zonas destinadas a control luminotécnico y grabación de vídeo y so. nido.

Con todo ello se ha conseguido aumentar la potencia de servicio del alumbrado espectacular en $660 \mathrm{kw}$, que se refleja en el suministro de 6 unidades de 24 dimmers de 2,5 kw, y 5 de 12 dimmers de $5 \mathrm{kw}$ para conseguir el nivel deseado (foto 15). Todo esto va regulado desde un pupitre de control y maniobra de los distintos efectos luminicos.

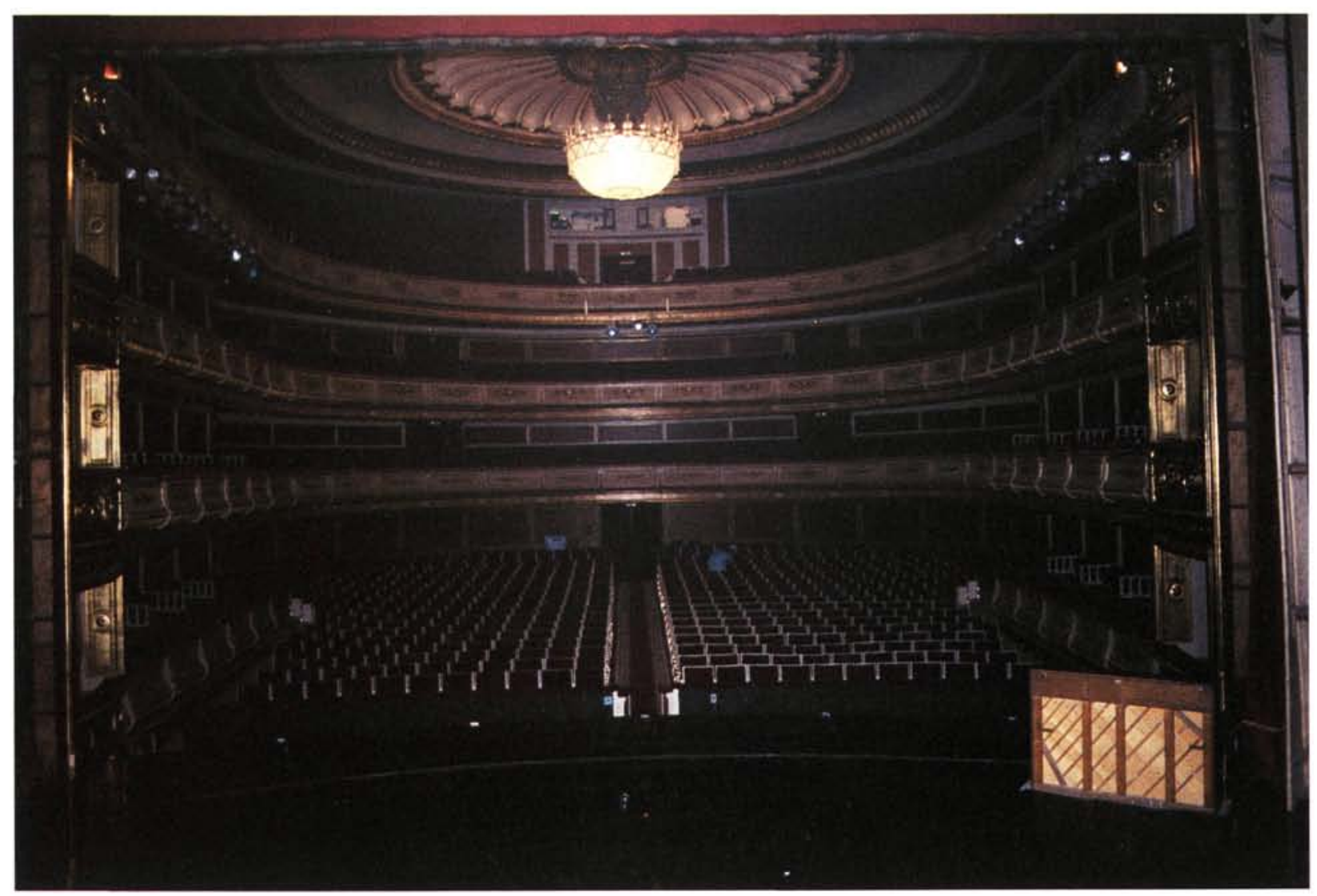

14. Vista general de la Sala desde el interior del escenario (estado definitivo). 


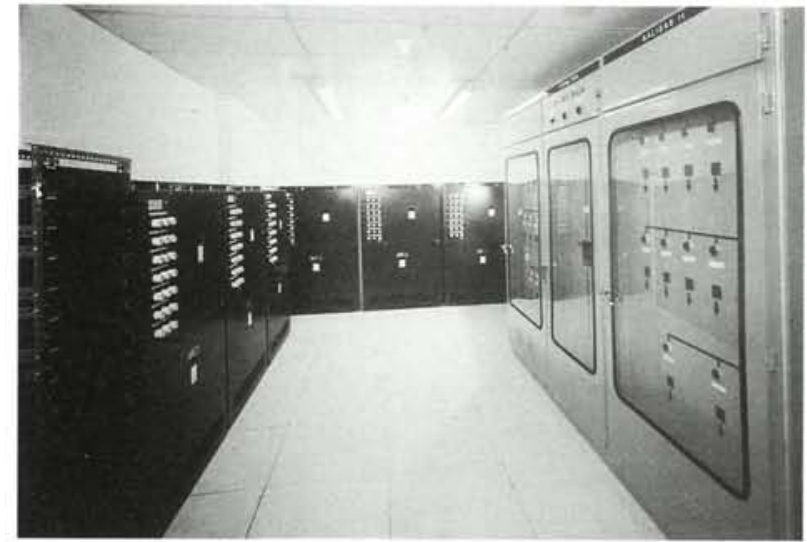

15. Gabinete de dimmers (control y regulación del alumbrado espectacular del escenario).

\section{Reforma de los camerinos}

Se acometió una reforma total en esta zona, la cual consta de distintos tipos:

- Camerinos de artistas principales en planta baja (foto 16$)$.

- Camerinos de artistas secundarios en planta primera.

- Camerinos de coros (colectivos) en planta segunda.

- Camerino del director de orquesta, despacho anexo y sala de reuniones en planta baja.

- Botiquin en planta baja.

- Camerinos o vestuarios de electricistas y tramoyis. tas (chácena).

Esta reforma consistió en una adecuación de espacios en determinados casos y, como ocurre en los camerinos de coros, en la creación de camerinos colectivos donde habia algunos individuales. Se instalaron espejos de maquillaje con luz regulable, nuevas mesas con lavabos incorporados para realizar en ellas las labores de maquillaje, bien hechas por los mismos actores o con la ayuda del equipo de maquilladores del Teatro (foto 16).

En los camerinos individuales, la compartimentación del paño de espejos permite ser utilizado, en determinados momentos, hasta por dos o tres actores. Todos los camerinos tienen instalación de intercomunicación con el regidor del escenario, permitiendo dar órdenes de entrada y salida a escena; megafonia general; co. nexiones TV y video. Esto último, con el monitor correspondiente, permite mantener un seguimiento en todo momento de lo que ocurre en escena durante una representación o un ensayo. La megafonia dispone de una línea que reproduce lo que se está representando en escena.

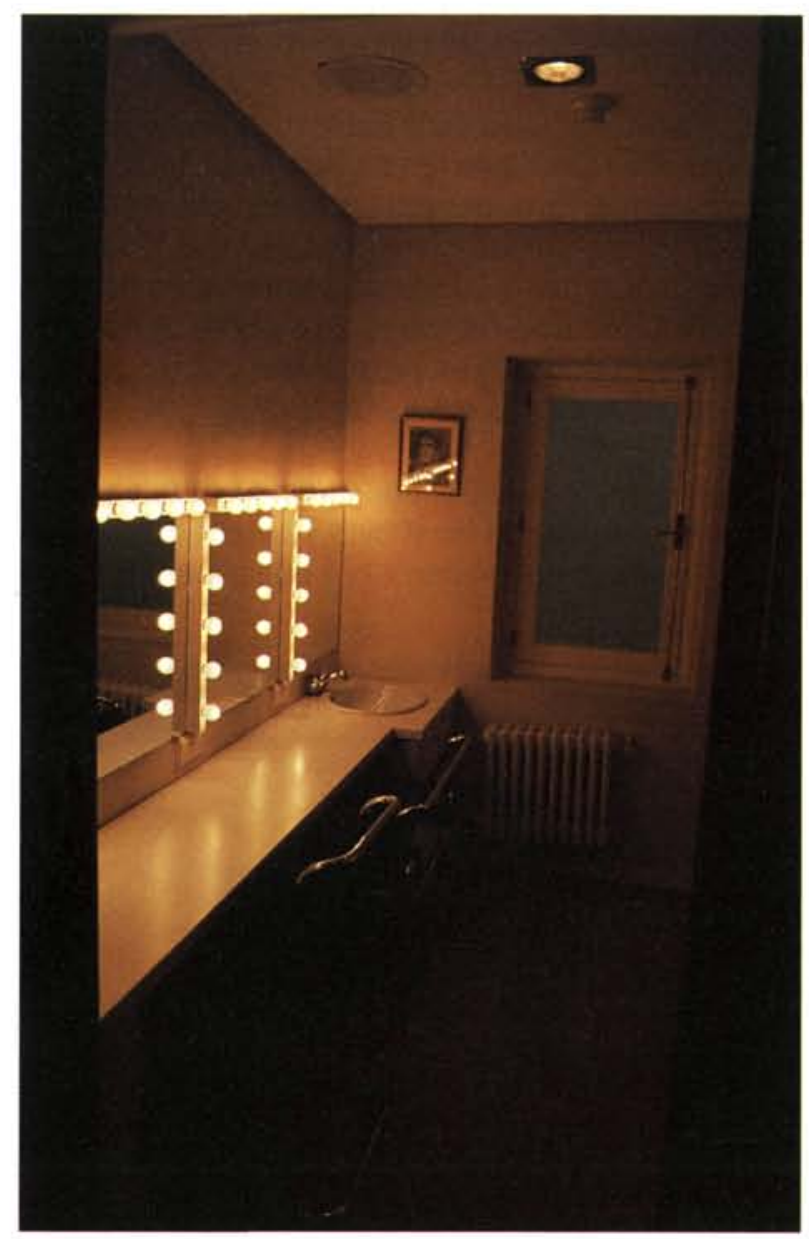

16. Vista de los camerinos.

\section{Reforma de la Sala y Vestibulos}

El trabajo realizado en la Sala y Vestibulos consistió en la restauración de pintura y molduras de escayola, consiguiendo los mismos tonos y colores que existian al comenzar la obra.

Se encontraron frisos y motivos decorativos en escayola totalmente rotos, los cuales hubo que rehacer, asi como reponer zonas, en la embocadura, donde había 
partes que hubo que restaurar con pintura en pan de oro (fotos 17 y 18).

Los pasillos de la zona de vestíbulos se trataron con pintura rayada (foto 19) y en el vestibulo del bar (foto 20) y se repuso el papel pintado de las paredes.

El mobiliario (butacas de la Sala y palcos) se restauró y tapizó con materiales ignífugos cumpliendo la Normativa vigente. Se renovaron las alfombras, moquetas, cortinas, todas con los mismos dibujos que tenian con anterioridad, reproduciéndolos fielmente. Se restauraron las 514 butacas de platea, las 570 de los anfiteatros, 180 en palcos, 30 en proscenios, y el tapizado de sofás en el vestíbulo del bar (foto 20).

La lámpara de la Sala General (fotos 17 y 21) fue motorizada. El movimiento de subida y bajada está regulado por un motor que soporta 1,2 t que pesa la lámpara.

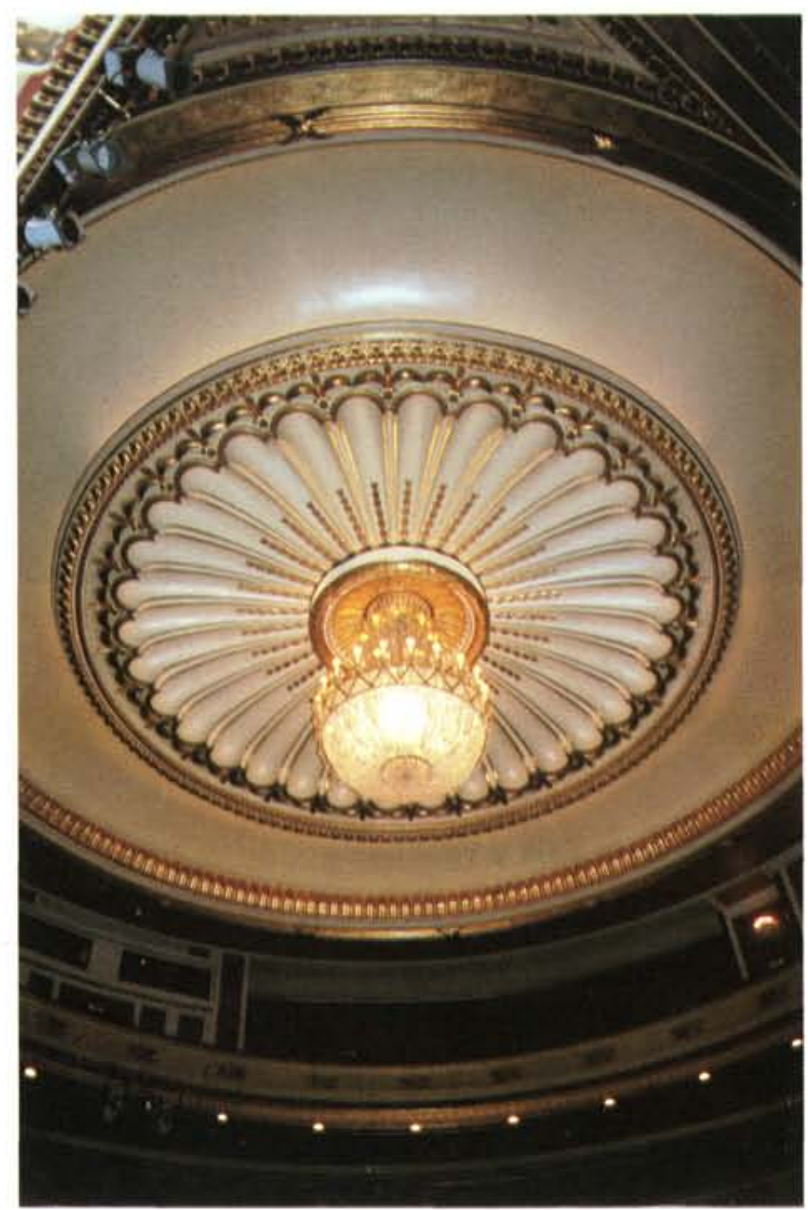

21. Detalle parcial del techo de la Sala con lámpara de iluminación.

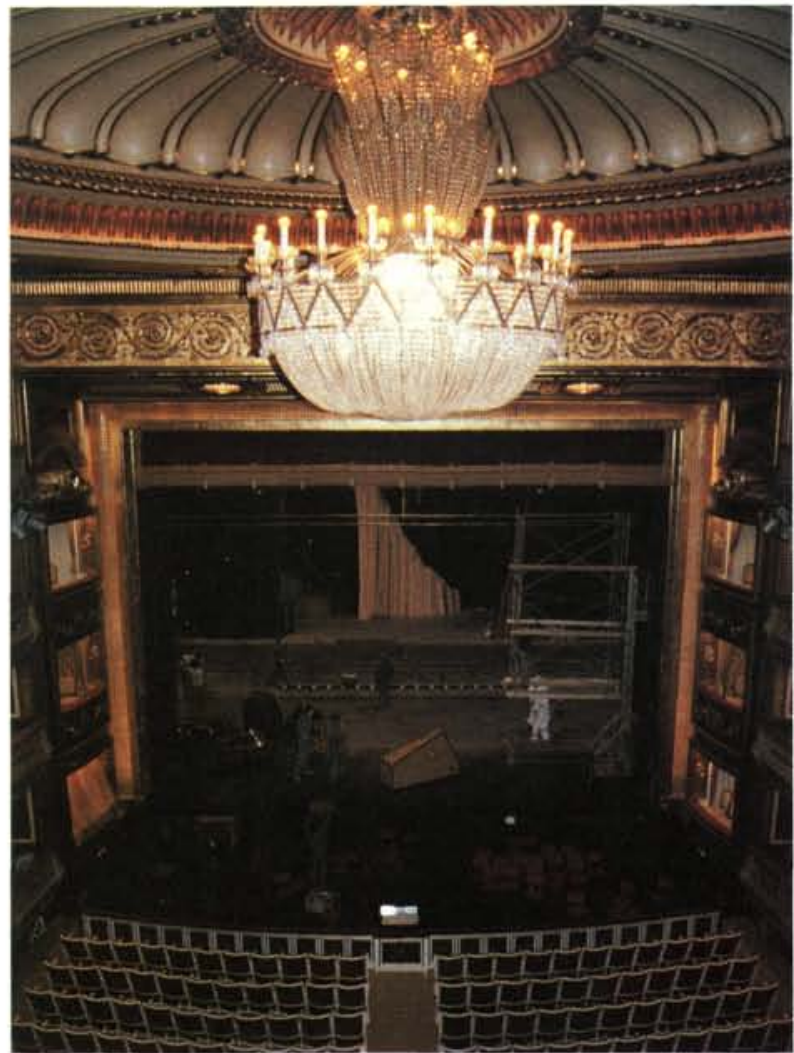

17. Vista general de la Sala (estado definitivo).

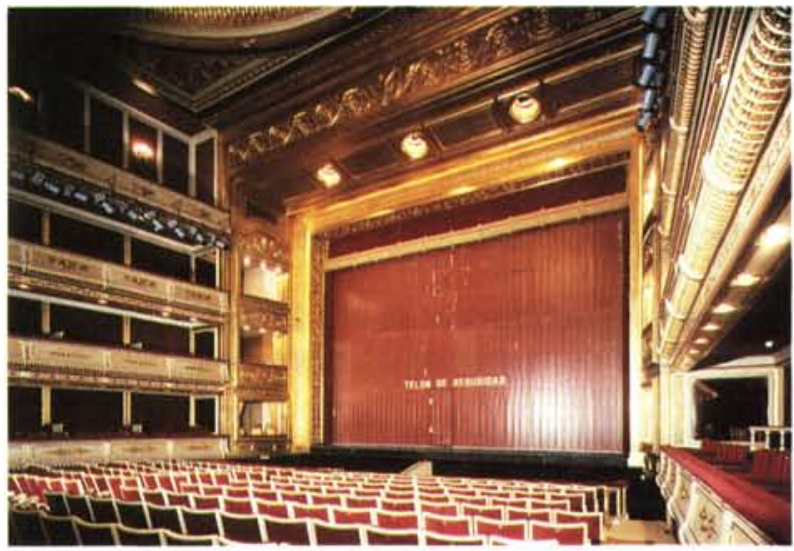

18. Vista general con el telón de seguridad (estado definitivo)

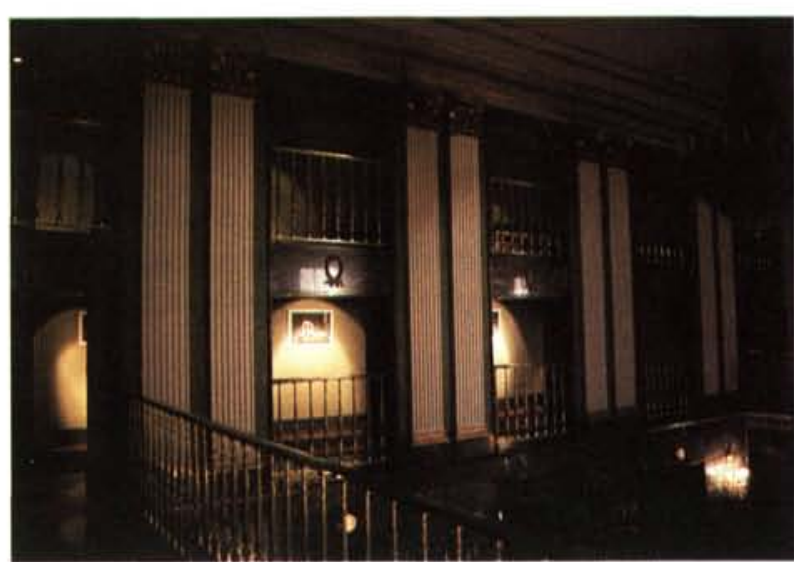

19. Vista parcial del vestibulo principal (estado definitivo) http://informesdelaconstruccion.revistas.csic.es 


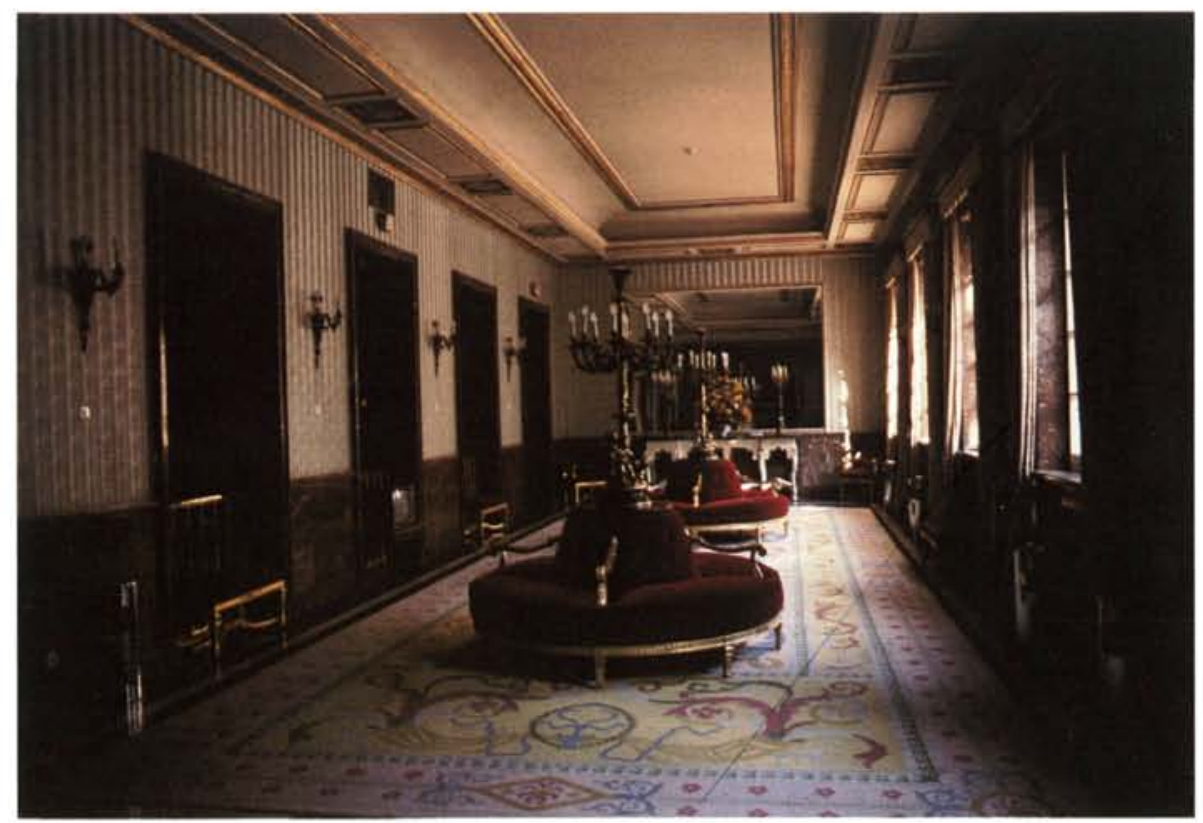

20. Vista del vestibulo del Bar (estado definitivo).

\section{Fachada}

En la fachada se siguieron los mismos criterios que en el interior. Se limpiaron paramentos y se rehicieron molduras en la ornamentación exterior para, posteriormen. te, proceder a pintar (fotos 22 y 23). Se instaló una iluminación que no existia con anterioridad y que, con las farolas de estilo "madrileño" y la pavimentación nueva en el retranqueo que produce la fachada con la alineación de las edificaciones colindantes de la calle Jo. vellanos, se ha creado un espacio muy atractivo constituyendo un antivestíbulo exterior del edificio. Sin llegar a ser una plaza, funcionalmente este espacio actúa como tal.

\section{Las instalaciones de seguridad}

\section{Alumbrado de emergencia y señalización}

Existia ya una instalación de este tipo anterior a la reforma, pero su nivel lumínico era muy escaso y el resto no cumplia, en ciertos aspectos, con la Normativa, como es la realización de su distribución por zonas.

Se completó en aquellos lugares donde era escasa, y se realizaron nuevos cuadros. Hoy todo el edificio tiene este tipo de iluminación, quedando perfectamente iluminados y señalizados todos los caminos de evacuación.

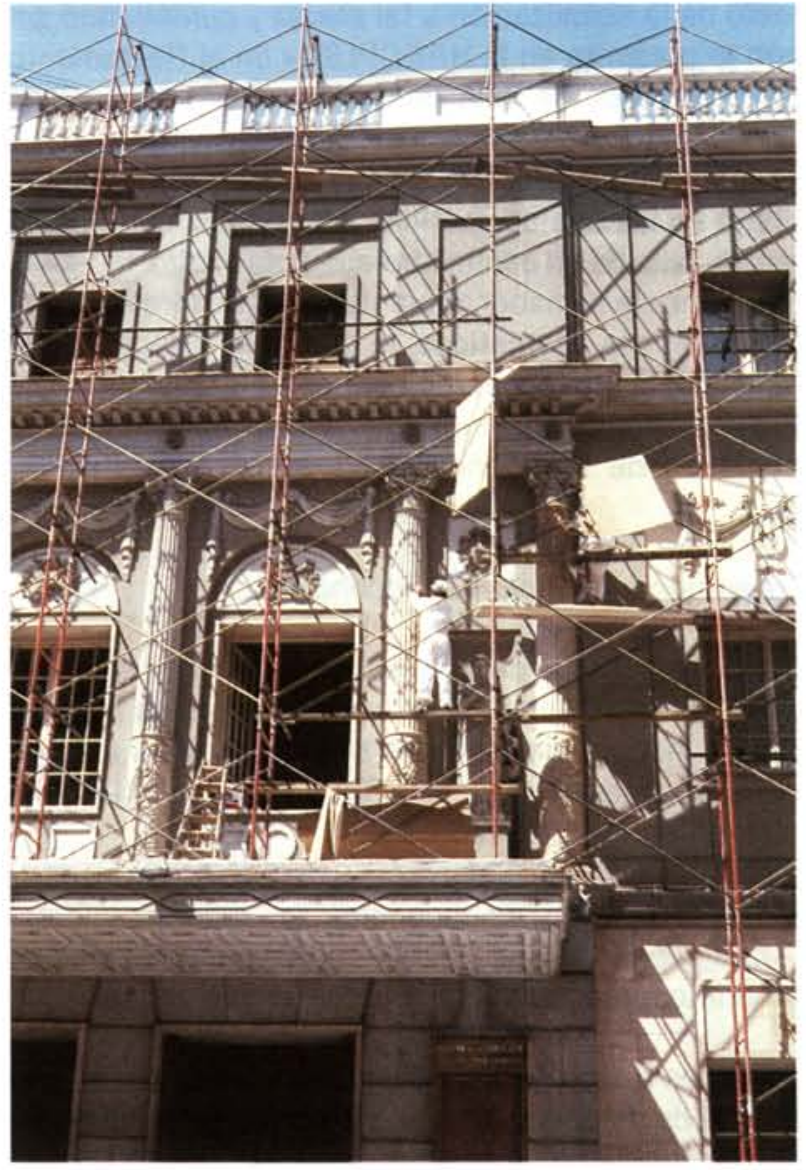

22. Trabajos de restauración y limpieza de la fachada principal. 


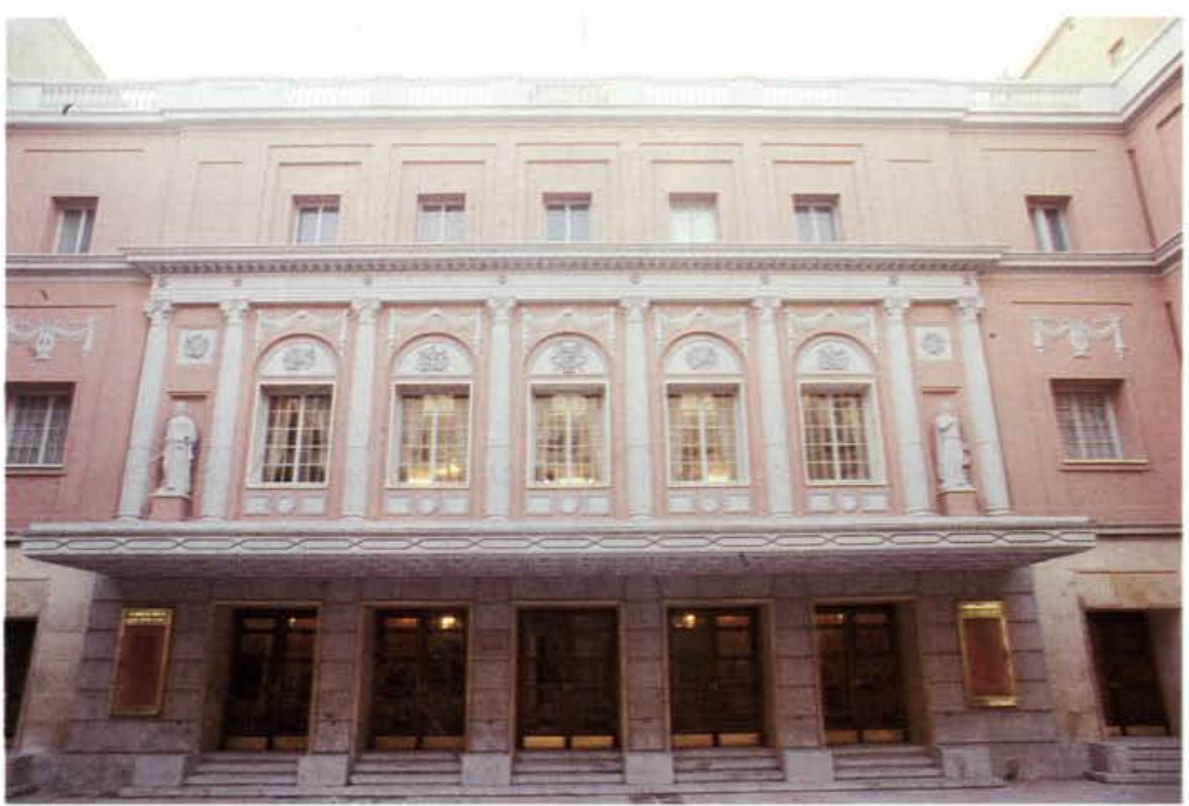

23. Vista de la fachada definitiva.

A la lámpara de la Sala (foto 21), se la dotó de puntos de alumbrado de emergencia, con lo que ante una eventual falta de suministro queda iluminada toda la Sala perfectamente y con el nivel adecuado para que el público pueda salir sin problemas, guiándose también del resto de la señalización a tal efecto y cumpliendo asi con lo prescrito en la NBE.CPI.82 y en el Reglamento Electrotécnico de Baja Tensión.

Al respecto se puede decir que se potenció el suministro en las dos acometidas del edificio, con lo cual ante la falta de un suministro quedaría el otro, independientemente de haber conmutado los cuadros generales de ambas acometidas, lo que quiere decir que si falla una, la otra acometida entraría en funcionamiento por conmutación, cubriendo asi las necesidades luminicas y de emergencia.

\section{Detección y extinción de incendios}

Desde el principio del acondicionamiento de este Teatro se pudo apreciar que esta instalación era muy escasa e incompleta. Tan sólo se circunscribia a determinadas zonas del escenario. Tras la reforma se ha com. pletado en su totalidad.

Existe detección de incendios en todo el edificio - cumpliendo la NBE.CPI.82- con detectores iónicos de humos y termovelocimétricos según zonas.

Todos los avisos de incendio quedan reflejados en una central de detección que existe en la conserjeria principal definida por zonas, con el fin de que en un momento determinado se sepa en qué estancia se ha pro- ducido un incendio y poder ser sofocado rápidamente. Esta conserjería es, además, una central de telefonía, tanto para el exterior como para el interior, con lo que un aviso a los bomberos se produciria inmediatamente.

La extinción es de varios tipos: por halón y por agua:

- Por gas halón es en aquellas zonas donde existe un material muy sofisticado, como pueden ser los cuadros generales de iluminación de escenario, acometidas, dimmers, cabinas de control de iluminación y de sonido e, incluso, las calderas. Se pensó en halón, pues es aquí donde una extinción por agua dañaria el material que se guarda en estos lugares, inclusive la instalación.

- Por agua, a través de una red de "sprinklers" se cubra todo el escenario y los fosos o sótanos del mismo, donde se almacena gran cantidad de material de maderas, telas, etc., que sirven para confeccionar decorados, así como en los desvanes del edificio.

Se dispuso, para esta instalación, de un aljibe con grupo de presión y con capacidad suficiente para suministrar agua a todos los puestos de extinción del edificio.

\section{El telón cortafuegos}

En la foto 18 se puede observar el telón cortafuegos, o de seguridad, que cubre la totalidad de la embocadura del escenario y que, ante un fuego, separa éste 
de la Sala General de Público. Se cumplió así con la NBE.CPI.82 y con el Reglamento de Espectáculos Públicos.

Ante un incendio, la detección por medio de los detectores del escenario se pone en marcha, aunque también se puede hacer manualmente; el mecanismo de bajada del telón se consigue mediante un motor hidráulico. Paralelamente a esto se cierran automáticamente las puertas del escenario, con lo cual, éste, que es el lugar donde las posibilidades de incendio son más altas, quedaría totalmente compartimentado del resto del edificio. Si a esto le añadimos que la estructura del escenario está ignifugada y la red de "sprinklers" es muy densa, la actuación devastadora del incendio quedaría sofocada rápidamente y no afectaría a otras zonas del edificio ni a propiedades colindantes.
Esto es, a grandes rasgos, lo que fue el acondicionamiento del Teatro Lírico Nacional "La Zarzuela", durante el período de 1983 a 1987.

\section{BIBLIOGRAFÍA}

- Guia de Arquitectura de Madrid (1800-1919). Págs. 20-21. Ramón Guerra de la Vega, 1980.

- Arquitectura Teatral en España MOPU, 1984.

- Catálogo de presentación de la Inauguración del Teatro Ĺ́rico Nacional "La Zarzuela". Serie Infraestructura n. 3. Ministerio de Cultura, 1986.

- Guia de Madrid. Colegio Oficial de Arquitectos de Madrid. Tomo l. Casco Antiguo. Edición mayo 1987.

DATOS DEL PROYECTO Y DE LA OBRA:

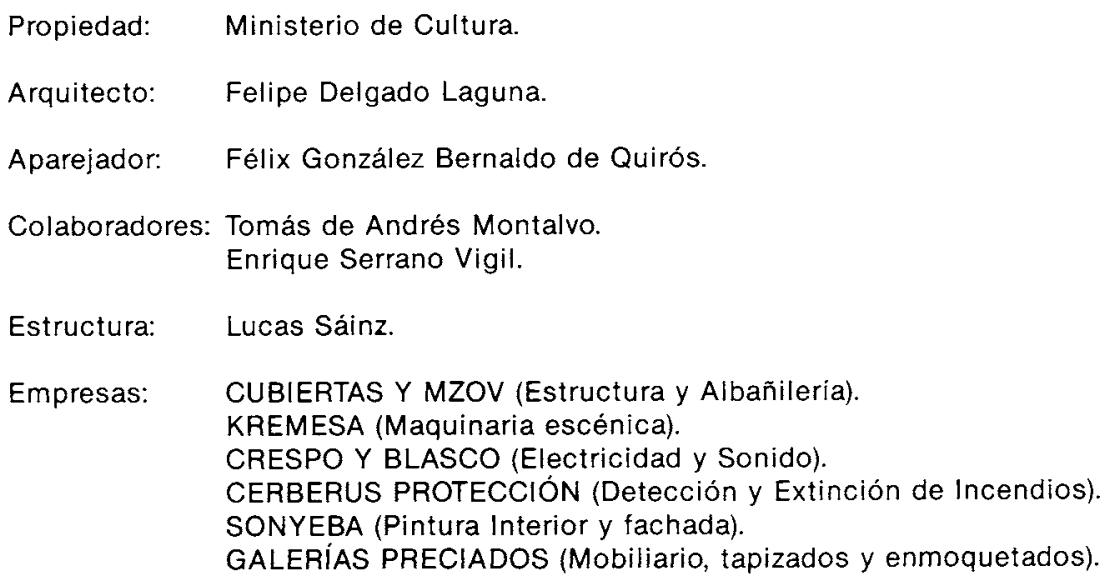

